\title{
Quel commerce fluvial en Loire angevine au XVIIIe siècle? Nantes et son arrière-pays ligérien
}

\section{Emmanuel Brouard}

\section{OpenEdition}

\section{Journals}

Édition électronique

URL : http://journals.openedition.org/abpo/3210

DOI : $10.4000 / a b p o .3210$

ISBN : 978-2-7535-5040-7

ISSN : 2108-6443

Éditeur

Presses universitaires de Rennes

Édition imprimée

Date de publication : 22 avril 2016

Pagination : 113-156

ISBN : 978-2-7535-5038-4

ISSN : 0399-0826

\section{Référence électronique}

Emmanuel Brouard, «Quel commerce fluvial en Loire angevine au XVIIle siècle ? Nantes et son arrièrepays ligérien », Annales de Bretagne et des Pays de l'Ouest [En ligne], 123-1 | 2016, mis en ligne le 22 avril 2016, consulté le 30 avril 2019. URL : http://journals.openedition.org/abpo/3210 ; DOI : 10.4000/ abpo.3210 


\title{
Quel commerce fluvial en Loire angevine au XVIII ${ }^{\mathrm{e}}$ siècle? Nantes et son arrière-pays ligérien
}

\author{
Emmanuel BROUARD \\ Docteur en histoire, chercheur associé au CERHIO \\ (Centre de recherches historiques de l'Ouest, UMR 6258) - \\ Adjoint du patrimoine à la bibliothèque municipale de Nantes
}

$\mathrm{Au} \mathrm{XVIII}{ }^{\mathrm{e}}$ siècle, la Loire est un axe commercial très important. Le faible coût du transport fluvial ${ }^{1}$ favorise des échanges intenses entre les villes riveraines, jusqu'au cœur du pays, depuis Nantes, porte de l'Atlantique, jusqu'à la Bourgogne, en passant par l'Orléanais. Des milliers de bateaux naviguent sur le fleuve. Pourtant, le détail de ce trafic fluvial est mal connu, surtout pour les régions proches de l'Atlantique. Sur la haute Loire, domine le commerce du bois, du vin et du charbon, essentiellement vers l'aval en raison des difficultés de navigation à la « remonte». Les relations avec Paris sont importantes, grâce au canal de Briare reliant la Loire au Loing, affluent de la Seine. En aval, entre l'Anjou et la Bretagne, circulent le tuffeau, le sel, le blé, le vin, le bois, les produits coloniaux. Mais l'importance relative de ces diverses productions reste imparfaitement connue.

L'objectif de cet article est de faire le point sur le commerce fluvial en Anjou. Quelles sont les marchandises concernées, et pour quels volumes? Quelle est l'importance relative du commerce local et celle du commerce de transit? Quelle est la place de Nantes dans ces échanges? Plusieurs types de sources seront utilisés. Les archives de l'intendance de Tours, de la

1. D'après Mantellier, le voiturage d'un tonneau de vin coûte 8 à 9 livres d'Orléans à Paris (en 1555), contre 1 livre et 4 sous d'Orléans à Tours (en 1549), pour une distance à peu près identique, autour de 130 kilomètres. Le rapport est de 1 à 7 . Dans l'autre sens, les vents d'ouest dominants permettent une remontée à la voile, ce qui compense des conditions peu propices au halage, en raison des variations du niveau de l'eau et des divagations du chenal. MANTELLIER, Philippe, Mémoire sur la valeur des principales denrées et marchandises qui se vendaient ou se consommaient en la ville d'Orléans au cours des $X I V^{e}, X V^{e}, X V I^{e}, X V I I^{e}$ et XVIII siècles, Orléans, Imprimerie Jacob, 1863 , p. 333 et 335 . 
Ferme générale et de la Chambre de commerce de Nantes ${ }^{2}$ contiennent de nombreux documents sur le sel, le vin, le sucre et le blé. On peut y trouver des informations ponctuelles sur les volumes transportés, mais aussi sur le contexte qui conditionne les échanges, et en particulier sur les interventions de l'État. J'ai aussi utilisé les procès-verbaux d'avaries, et les journaux du péage de la " cloison d'Angers ", dont deux bureaux de perception sont situés sur la Loire. La première partie de l'article est consacrée à la présentation de la manière dont sont utilisées ici ces deux sources principales : comment sont constitués les échantillons, quels sont les problèmes et les biais induits par ces sources? La deuxième partie présente les grands axes du commerce tels qu'ils ressortent de l'observation des procès-verbaux. Les marchandises qui circulent sont ensuite étudiées pour l'Anjou et la Touraine, puis du point de vue nantais. Enfin, la dernière partie est consacrée à une estimation globale du trafic, fondée sur les journaux du péage de la cloison, pour les années 1753, 1761 et 1766 .

\section{Des sources fragmentaires pour une étude sérielle des produits, des volumes et des trajets}

\section{Les journaux de la " cloison d'Angers » : apports et limites}

La cloison d'Angers fait partie des nombreux péages qui ont fonctionné sur la Loire jusqu'à la Révolution française ${ }^{3}$. Les droits sont perçus dans plusieurs bureaux, situés à Angers et dans la région : aux portes de la ville (portes Cupif, Saint-Aubin, Lyonnaise, etc.), sur la Maine à l'entrée et à la sortie de la ville (Haute Chaîne et Basse Chaîne), à sa confluence avec la Loire (La Pointe, à Bouchemaine), aux Ponts-de-Cé sur le fleuve, et enfin à Ingrandes, une quarantaine de kilomètres en aval. Les deux derniers bureaux sont de loin les plus importants, en raison des nombreuses marchandises circulant sur le fleuve. Les voituriers par eau ou par terre ne paient qu'au premier bureau franchi, en entrant dans la zone entre Angers, Ingrandes et Les Ponts-de-Cé. S'ils franchissent un second bureau, un " acquit " établi au premier les dispense de payer de nouveau.

2. Arch. dép. de Loire-Atlantique, série C. Chambre de commerce de Nantes. Arch. dép. d'Indre-et-Loire, série C. Intendance de la généralité de Tours. Arch. nat., sous-série G1. Ferme générale.

3. Ce péage est créé en 1344, par le duc d'Anjou, afin de financer des réparations à faire aux fortifications d'Angers. Au Xv ${ }^{\mathrm{e}}$ siècle, la gestion en est laissée à la ville. Un doublement, puis un triplement du droit de cloison sont accordés par la monarchie au XVII ${ }^{\mathrm{e}}$ siècle, mais un arrêt du 14 juillet 1663 réunit à la ferme des Aides les double et triple cloisons, laissant la "simple cloison " à la municipalité. Longtemps affermée, la simple cloison est administrée en régie à partir de 1736. La perception est abandonnée en 1790. Monique Merlet et Johann Audoin ont étudié la cloison d'Angers. Le recueil des privilèges de la ville publié en 1748 est aussi une source précieuse d'informations. MERLET, Monique, Le péage de la cloison d'Angers. Histoire d'un impôt municipal. Aperçu du trafic de Loire au XVIII ${ }^{e}$ siècle, thèse de l'École des chartes, 1967. AudoIN, Johann, La perception de la cloison d'Angers : 1656-1791, mémoire de maîtrise, université d'Angers, 2001. ROBERT, René, Recueil des privilèges de la ville et mairie d'Angers, Angers, L.C. Barrière, 1748. 


\section{Figure 1 -Marchandises circulant sur la Loire et principaux bureaux de la cloison}

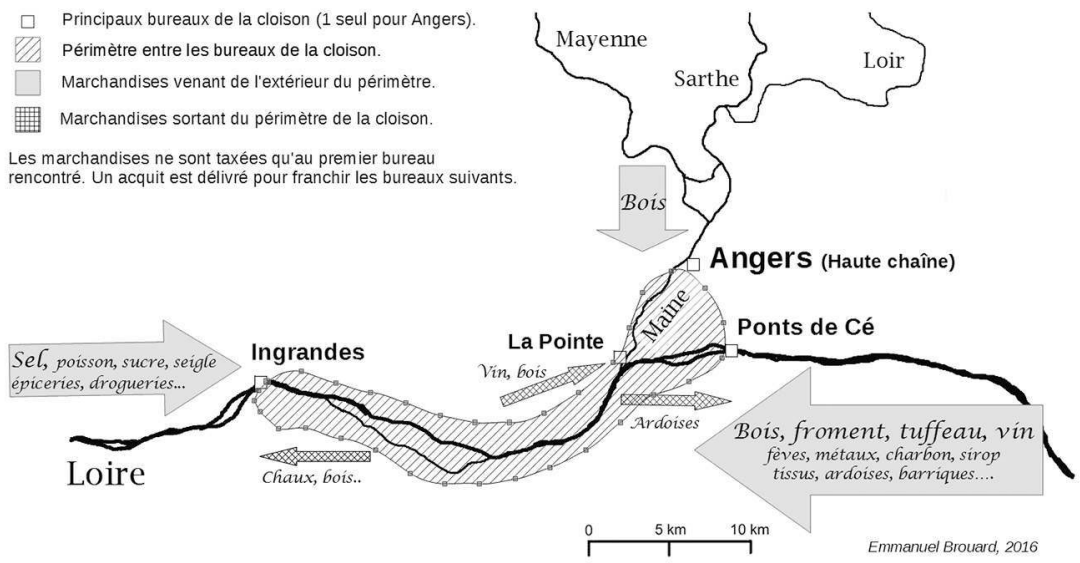

Sources : Arch. mun. d'Angers, CC 202 (journaux de 1753), CC 30 (1761), 31 et 32 (1766)

Des « journaux " du péage de la cloison sont conservés pour un petit nombre d'années : du second semestre 1751 au début de 1755, ainsi que pour 1761 et 1766. Ces journaux sont de petits cahiers de quelques pages ou, pour les petits bureaux, des feuilles isolées, comprenant, pour chaque mois, le nom des particuliers se présentant pour payer la taxe, leur résidence, et les marchandises concernées. Aux Ponts-de-Cé, les destinations sont aussi indiquées (annexe 4), ce qui n'est pas le cas à Ingrandes. Ces journaux sont une source précieuse pour l'étude du trafic fluvial.

L'utilisation de ces journaux pose pourtant quelques problèmes. Au XVIII ${ }^{\mathrm{e}}$ siècle, la perception est fondée sur une " pancarte " établie en janvier 1657. Elle détaille les montants réclamés pour 228 produits, en fonction de leur poids, de leur conditionnement ou de leur valeur. L'évaluation de la masse des marchandises est délicate lorsque la taxe est perçue en fonction de leur valeur; c'est le cas entre autres des pierres à fusils, des sirops de sucre et des confitures. Il faut alors découvrir les prix pratiqués à l'époque pour établir des concordances. D’autres difficultés sont liées au conditionnement très varié des produits. Le poids d'un baril de farine ou d'une barrique de vin est facile à déterminer, mais combien pèse une peau de bœuf? Une " grosse " de sabots ${ }^{4}$ ? Un " cent " ou un " millier " correspondent parfois à 100 ou à 1000 livres pesantes, mais d'autres fois, à une quantité d'unités (pour l'ardoise), ou à une valeur arbitraire encore différente. Ainsi, le " cent " de morue verte est composé de 124 morues ou 62 poignées de 2 , pesant 600 à 900 livres pour les deux premières qualités, ce qui donne un

4. La grosse de sabots est composée de 156 paires, évaluées ici à $246 \mathrm{~kg}$. 
poids moyen de $367 \mathrm{~kg}^{5}$. On peut trouver ce type d'informations dans des publications des $\mathrm{XVIII}^{\mathrm{e}}$ et XIX ${ }^{\mathrm{e}}$ siècles. Quelques énigmes subsistent : combien pèse une "fourniture " de cercles de barriques? À quelle masse correspondent 1542 livres tournois d'arbres fruitiers descendant d'Orléans? Ou 1391 livres de chevilles de bois? Heureusement, ces incertitudes sont peu de chose par rapport à l'évaluation globale qui porte sur plusieurs dizaines de milliers de tonnes (Annexes 5 et 6). Le sel est dispensé de ce péage et n'apparaît donc pas dans les journaux de la cloison. On sait cependant que les entrées de sel dans le port de Nantes sont importantes, et qu'elles augmentent au cours du XVIII ${ }^{\mathrm{e}}$ siècle, en lien avec l'accroissement de la population : 7824 tonneaux en 1732, 12447 tonneaux en $1772^{6}$, 13242 tonnes en $1788^{7}$. Des estimations de 10000 tonnes en 1753 et de 11500 tonnes en 1766 paraissent acceptables.

\section{Les procès-verbaux d'avaries et de retards : une approche du commerce au ras de l'eau}

Les procès-verbaux d'avaries constituent une source complémentaire très riche mais peu utilisée ${ }^{8}$. Les avaries sont liées principalement à des obstacles immergés, à des échouages dus aux intempéries (tempêtes, glaces), à des heurts entre bateaux et au franchissement redouté des ponts aux Ponts-de-Cé 9 . D'autres procès-verbaux concernent des retards de livraison, la durée des voyages étant très aléatoire : la navigation est souvent interrompue par les crues, les basses eaux ou les vents contraires. En cas d'avaries, les "voituriers par eau " auxquels les marchands confient leurs marchandises demandent à des notaires de dresser des procès-verbaux, afin de se justifier et de ne pas être tenus pour responsables des pertes occasionnées. Un échantillon fondé sur 263 procès-verbaux dressés par des notaires résidant entre Ancenis et Montsoreau, mais principalement entre Angers et Saumur, a été retenu. Ils s'échelonnent entre 1689 et 1792, mais la plupart sont postérieurs à $1750^{10}$.

5. SaVAry des Bruslons, J. et SAVARY, Philémon-Louis, Dictionnaire universel de commerce..., Paris, Jacques Estienne, 1723, tome second, article « morue ", p. 795.

6. Michon, Bernard, Le port de Nantes au XVIII ${ }^{e}$ siècle : construction d'une aire portuaire, Rennes, PUR, 2011, p. 217 et annexe VII.

7. 5750 muids de sel sont chargés à Nantes pour la Loire " amont " en 1788. Le muid pèse environ 4700 livres. Arch. nat., G 1/97. Voiture du sel. Deuxième année du bail Mager, 1788.

8. Françoise de Person s'en est servie pour l'étude de la navigation et des relations commerciales, principalement en région Centre. PERSON, Françoise de, Bateliers sur la Loire. XVII -XVII ${ }^{e}$ siècles. La vie à bord des chalands, Chambray-les-Tours, 1994, 268 p.

9. Dans un article précédent, je me suis fondé sur un échantillon de 231 procès-verbaux pour étudier les conditions de navigation et d'avaries. BROUARD, Emmanuel, « La navigation en Loire au XVIII ${ }^{\mathrm{e}}$ siècle vue à travers les procès-verbaux d'avaries ", Annales de Bretagne et des Pays de l'Ouest, 2005, vol. 112, n³, p. 37-69.

10. 33 procès-verbaux relatifs à des retards, 153 à des naufrages complets, 69 à des avaries simples, 5 à des avaries de marchandises seules, et 3 à des cas particuliers. 9 concernent des radeaux de bois, et tous les autres des bateaux. Sur 263 procès-verbaux, 


\section{Figure 2 - Localisation des avaries, naufrages et retards, d'après 263 procès-verbaux. 1689-1792}

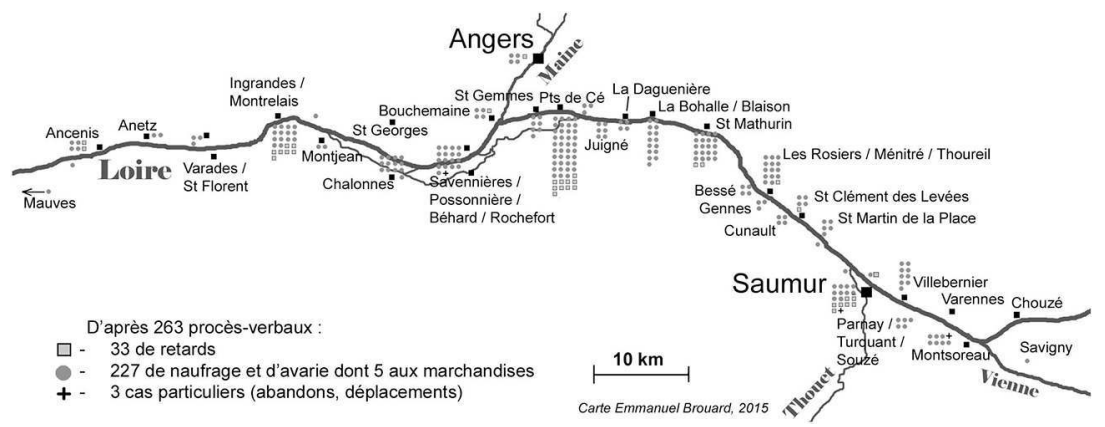

Sources : Arch. dép. de Maine-et-Loire, sous-série 5E. Actes notariés

Ces documents nous renseignent sur la résidence des voituriers, la nature des marchandises, les expéditeurs et les destinataires, ainsi que sur les conditions de navigation, d'avaries et de sauvetage. Ils donnent donc un aperçu du trafic, mais ils induisent certains biais qu'il faut garder en mémoire. La nature des chargements ne joue que très rarement sur les accidents. Par contre, une fois que l'eau s'est engouffrée dans les bateaux, certaines marchandises, telles le sel, le blé et le sucre, sont plus vulnérables que d'autres, comme l'ardoise, le tuffeau et le vin ${ }^{11}$. Pour autant, cela n'entraîne pas d'écarts dans la fréquence des procès-verbaux : si 30 centimètres d'eau pénètrent dans un chaland chargé de vin ou d'ardoises, la marchandise est peu affectée, mais cela se voit à l'arrivée, et le voiturier a tout intérêt à demander un procès-verbal. De plus, les deux tiers des procès-verbaux concernent des bateaux entièrement submergés; la rédaction d'un procès-verbal est alors inévitable. Deux produits sont cependant sousreprésentés au regard de l'importance du trafic les concernant. Le premier produit est le sel. Son transport est surveillé de près par l'administration. Bien que certains voituriers fassent appel à des notaires en cas d'accident $^{12}$, Françoise de Person a observé que, pour les zones comprises dans l'actuelle région Centre, la plupart s'adressent aux officiers des greniers à

135 concernent des bateaux remontant la Loire, 124 des bateaux descendant, et 4 des bateaux dont le sens de circulation n'est pas précisé.

11. En 1766, des barriques de vin sont emportées par une crue, apparemment depuis le port de Blois. Le commis du négociant part à leur recherche et retrouve 53 pièces sur 68, stockées chez un marchand de Saumur. Malgré ce périple, 38 pièces sont jugées de bonne qualité par des experts; 6 autres sont vides, et 9 ne méritent pas le transport (Arch. dép. de Maine-et-Loire, 5E69/468. Minutes Jouanne, notaire à Saumur, PV du 23/12/1766).

12. Une intervention commune apparaît dans un acte du $1^{\mathrm{er}}$ juillet 1782 . Requis par un voiturier, un notaire se rend sur le lieu d'un naufrage à Anetz et interroge les témoins. Mais le receveur des gabelles de Saint-Florent-le-Vieil se présente dans l'après-midi : « Il nous a dit de procéder conjointement avec lui à l'examen de la cause de l'accident dont il s'agit et à l'état dans lequel se trouvent maintenant les sacs de sel ", et cela à la réquisition expresse du voiturier. "Nous les avons trouvé fleurdelisés plombés bobinés et sans 
sel ${ }^{13}$. Résultat : si le sel représente plus du tiers du trafic vers l'amont en 1753 (voir en fin d'article), il n'est présent que dans 7 procès-verbaux sur 93 relatifs aux marchandises remontant de Nantes (7,5\%), dont 3 rédigés entre l'automne 1789 et 1791, c'est-à-dire après l'abandon de la perception de la gabelle en Anjou à l'été 1789. Le tuffeau paraît lui aussi sousreprésenté, cette fois en raison du commerce entrepris pour leur propre compte par des voituriers du Saumurois ${ }^{14}$. En cas d'accident, ils n'ont pas besoin de se justifier auprès de négociants. Enfin, les radeaux de bois, ou " eschargeaux ", constituent un cas particulier. Une partie du bois circule en bateaux, mais une autre est assemblée en radeaux. La fréquence des avaries subies par ces radeaux, rapportée à celles des bateaux, n'est pas connue. Malgré leurs limites, les procès-verbaux permettent de faire ressortir les grands courants de circulation ainsi que les principales marchandises, sur une longue durée, et d'attirer l'attention sur certaines caractéristiques du trafic en Anjou.

\section{Nantes domine le commerce en Loire angevine, ses relations sont étroites avec Orléans et avec l'Anjou}

Venons-en aux grands mouvements révélés par les procès-verbaux. Nantes occupe une place centrale dans ces échanges. C'est de là que proviennent 73,6 \% des marchandises envoyées vers l'amont, à la "remonte " (95 chargements sur 129 d'origine connue $)^{15}$. Près de la moitié des marchandises venues de Nantes vont à Orléans ${ }^{16}$ : c'est le cas de 56 chargements sur 119 dont la destination est connue (47,1\%), dont 46 sur 83 sont partis de Nantes (55,4 \%). Par contre, aucun bateau n'est dirigé en amont d'Orléans sur la Loire. Ce port est un relais entre la Loire d'aval, la haute Loire, Paris et l'est de la France. Les négociants orléanais sont principalement des commissionnaires, jouant un rôle d'intermédiaires en échange d'un pourcentage sur la transaction. Une " rupture de charge " a souvent lieu : les marchandises sont débarquées, séjournent dans des entrepôts, avant d'être rechargés sur d'autres bateaux, ou sur des charrettes, car de nombreuses marchandises

aucune rupture ny couture à l'extérieur, en un mot conformes à l'état annoncé par le brevet " (Arch. dép. de Loire-Atlantique, 4E 31/259. Minutes Lebec, Ancenis).

13. Malheureusement, les greniers à sel ont laissé peu d'archives en Anjou (PERSON, Françoise de, Bateliers contrebandiers du sel : XVII ${ }^{e}$-XVIII ${ }^{e}$ siècles, Rennes, Ouest-France, 1999).

14. D'après un mémoire de 1751, " les voituriers venant à vides chercher des sucres et autres marchandises, ils acheptent eux même et pour leur compte les tuffeaux sur les perrieres " [afin d'avoir un chargement à la descente] (Arch. dép. de Loire-Atlantique, C 878. 18/6/1751. Mémoire relatif à une tentative de monopolisation des tuffeaux blancs).

15. 135 bateaux remontent la Loire, 5 sont de provenance inconnue, et 16 de destination inconnue.

16. Destination des bateaux à la remonte : 11 Angers. 1 Ponts de Cé. 6 Chinon (1 arrêt à Saumur). 6 Saumur. 1 Chouzé (près de Saumur). Plusieurs font des arrêts entre Saumur, Tours et Orléans. 11 Tours. 1 Amboise. 2 Blois. 1 Saint-Aignan-sur-Cher. 56 Orléans. 1 SaintMesmin (près Orléans). 2 Montargis (canal d'Orléans). 7 Châtellerault (1 arrêt à Chinon, 1 à Saumur). 9 Paris et Bercy. 1 Mazière. 
prennent la route pour atteindre Roanne et Lyon au sud, ou Paris au nord. Les ruptures de charge tiennent à la position d'Orléans, sur un coude de la Loire près de Paris, mais aussi aux contraintes de la navigation en amont : les vents étant moins favorables, on recourt plus souvent au halage, ce qui demande davantage de personnel et de temps, augmente le coût et complique la tâche des mariniers venus de l'aval ${ }^{17}$. Les relations sont plus faciles avec Paris, grâce au canal de Briare et au canal d'Orléans construits au $\mathrm{XVII}^{\mathrm{e}}$ siècle ${ }^{18}$ : neuf chargements vont directement à Paris ou ses environs (Bercy), dont quatre d'ardoises d'Angers, quatre de vins du Saumurois, et un d'épiceries de Nantes. Les quais de Paris reçoivent les bateaux et marchandises de la haute Loire et du Lyonnais d'une part, des provinces de l'Ouest et de l'Atlantique d'autre part. Depuis Orléans, Paris est desservi par la route pour le sucre, et par le canal pour l'ardoise.

Parmi les chargements dirigés vers l'amont, quinze partent d'Angers $(12,3 \%)$, et les dix-neuf restants, de divers secteurs de l'Anjou ${ }^{19}$. Le port d'Angers est intégré au trafic fluvial ligérien. Situé sur un affluent, la Maine, à quelques kilomètres de la Loire, il constitue non seulement une escale pour les bateaux naviguant sur le fleuve, mais aussi un point de rupture de charge et un relais pour les échanges avec les bassins de la Mayenne, de la Sarthe et du Loir. En effet, les bateaux de Loire ne sont pas assez robustes pour passer les "portes marinières " situées sur ces rivières. Des voituriers d'Angers utilisent pour cela des bateaux spécialisés, nettement plus solides, appelés havriers, hannequins et gabarres, que l'on ne retrouve pas en aval d'Angers ${ }^{20}$. Les équipages sont aussi plus nombreux. Il faut attendre la construction d'écluses au milieu du XIX ${ }^{\mathrm{e}}$ siècle pour que les bateaux de Loire remontent en amont d'Angers.

Parmi les destinations vers l'aval (à la " descente "), Nantes domine encore largement, avec 99 chargements sur 119 dont la destination est

17. Dans un mémoire un peu postérieur à 1785 , les entrepreneurs de la " voiture du sel » indiquent que la navigation se fait " par le tirage depuis Orléans. Une équipe, qui est montée par 14 hommes d'équipage en partant de Nantes [pour 6 ou 7 bateaux], en prend d'abord en outre 40 à Orléans pour se faire hâler; cette seconde quantité est ensuite renforcée de distance en distance par 60 hommes. Elle employe communément 4 à 5 mois pour se rendre de Nantes à Digoin, port de décharge des sels qui fournissent les greniers du Charolois, de Chalon et d'une partie de la Saonne jusqu'à la Franche-Comté ". Le fret de Nantes à Orléans coûte de 10 à 12 livres du mille pesant, contre 40 à 50 livres au moins d'Orléans à Roanne, " qui sont en très petite quantité " (Arch. nat., G1/97. Mémoire concernant la navigation des rivières, par les entrepreneurs de la voiture des sels pour les greniers de grandes gabelles. Publié dans les Annales de Bretagne, tome 36, 1924-1925).

18. Le canal de Briare, ouvert en 1642, relie la Loire au Loing, un affluent de la Seine. Le canal d'Orléans (1692) commence une dizaine de kilomètres en amont de cette ville et rejoint le Loing près de Montargis.

19. 6 des Ponts-de-Cé et de Sorges, 3 du Saumurois, 2 de Saint-Mathurin, 1 de Chalonnes, Montjean et Ingrandes.

20. Le mot " gabarre " désigne aussi les bateaux faisant la navette entre Nantes et les ports situés en aval (Paimboeuf, Saint-Nazaire). Cependant, ces embarcations ventrues sont radicalement différentes des fins bateaux utilisés sur la Loire en amont de Nantes. Ils ressemblent plutôt aux chaloupes et chasse-marées du petit cabotage. 
Figure 3 - Destinations des bateaux partis de Nantes (" ̀̀ la remonte "), d'après 83 procès-verbaux d'avaries

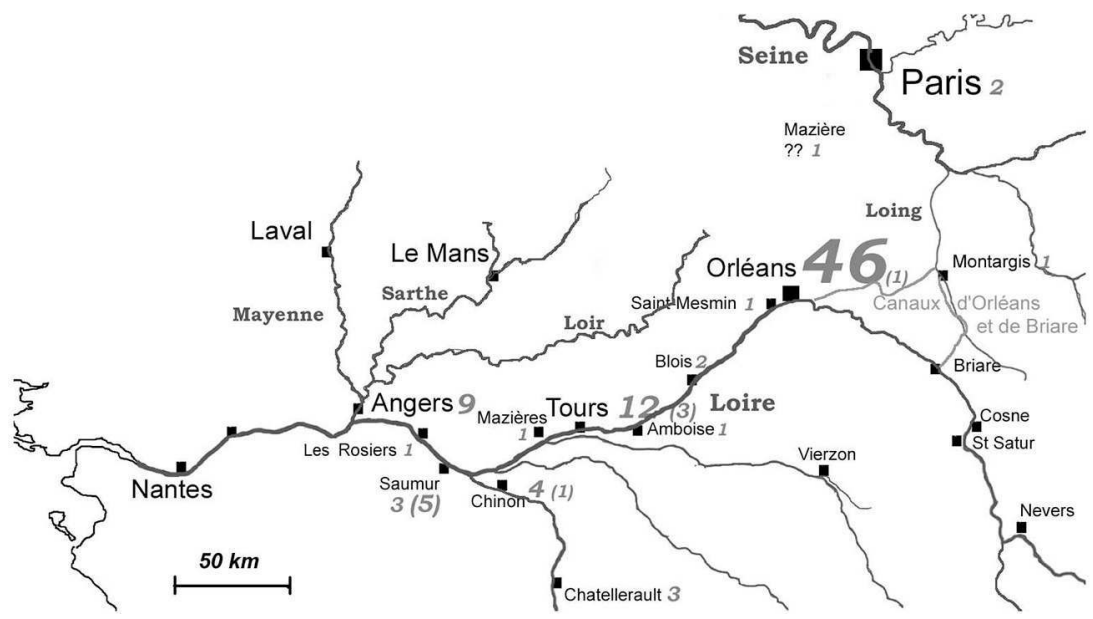

Sources : Arch. dép. de Maine-et-Loire, sous-série 5E. Actes notariés. Procès-verbaux d'avaries, naufrages et retards de livraison. 83 destinations communes. Entre parenthèses : les arrêts en cours de route.

connue $(83,2 \%)^{21}$. Douze autres chargements ont Angers pour destination finale. Le Saumurois est le principal fournisseur de Nantes : 26 bateaux sur 86 viennent de Saumur et du Saumurois, entre Chouzé et Gennes $(30,2 \%)^{22}$, dont 17 chargés de blés. Si on ajoute le secteur aval de l'Anjou, jusqu'à la limite de la Bretagne, on arrive à 36 chargements sur 86 provenant de l'Anjou $(41,8 \%)$. Orléans vient derrière, avec 15 chargements (17,4\%), suivi par Tours ( 7 chargements), Blois (4), puis un chapelet de villes et de villages. La haute Loire et l'Allier apparaissent ici avec huit chargements, car Orléans ne joue pas à la descente un rôle de filtre aussi marqué qu'à la remontée : les voituriers de l'amont ont intérêt à aller le plus loin possible vers l'aval, sachant que la plupart des bateaux ne remonteront pas en haute Loire : ils seront " déchirés " pour servir de bois d'œuvre, ou revendus sur le marché d'occasion, dans ces " pays bas " où le prix du bois est nettement plus élevé que sur les rives de la haute Loire et de l'Allier. Des bois et des fers de ces régions atteignent Nantes, ainsi qu'un peu de charbon, de Decize en particulier ${ }^{23}$; cependant, la région nantaise, l'Anjou et le Poitou consomment principalement des char-

21. Sur 110 bateaux descendant la Loire, 14 sont de provenance inconnue, et 5 sont de destination inconnue.

22. Sur 99 bateaux descendant vers Nantes, 13 sont d'origine inconnue.

23. Archives dép. de Loire-Atlantique, C 773, décembre 1737. Observations des juges et consuls de Nantes sur un mémoire des entrepreneurs des mines de charbon d'Auvergne et du Bourbonnais. 
bons anglais, de meilleure qualité, moins chers et plus faciles à se procurer que ceux de l'amont.

Figure 4 - Destinations des bateaux partis vers Nantes (“ à la descente "), d'après 86 procès-verbaux d'avaries

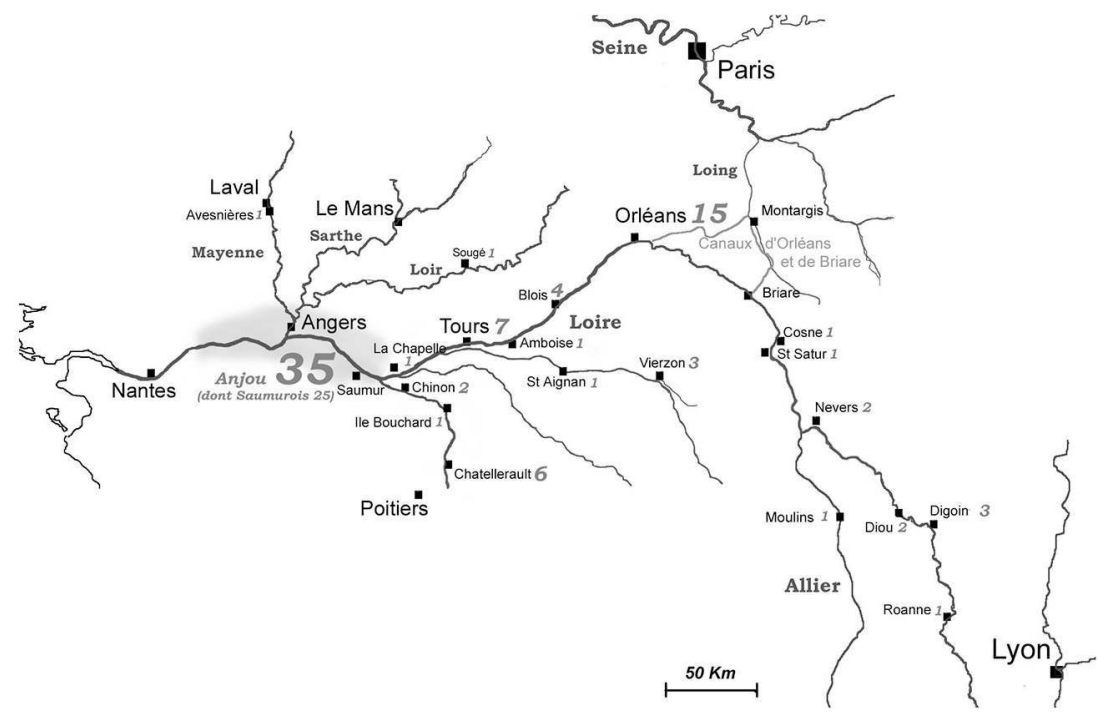

Sources : Arch. dép. de Maine-et-Loire, sous-série 5E. Actes notariés. Procès-verbaux d'avaries, naufrages et retards de livraison (86 lieux de chargement connus, sur 99 voyages).

En résumé, on observe à la montée un transport fluvial centré sur les relations Nantes-Orléans ${ }^{24}$, coexistant avec des échanges locaux. Par contre, à la descente, l'Anjou est le principal partenaire de Nantes. Les figures 3 et 4 représentent l'origine géographique des bateaux partis de Nantes et celle des bateaux dirigés vers ce port.

\section{L'Anjou et la Touraine exportent par la Loire} leurs productions agricoles et leurs matériaux de construction

\section{Les facilités du transport fluvial et la proximité de Nantes favorisent la commercialisation des productions angevines}

L'Anjou profite largement des facilités du transport fluvial. Grâce à la Loire, Angers exporte des ardoises, le Saumurois du blé, du vin, du tuffeau,

24. L'importance de cet axe doit être un peu tempérée par la rareté du sel dans les procès-verbaux, alors que ce produit est diffusé dans tout le bassin fluvial. Cependant, une présence du sel plus conforme à la réalité du trafic ne remettrait pas en cause la primauté de l'axe Nantes-Orléans à la remonte. 
des amandes, des pruneaux ${ }^{25}$, du chanvre de la vallée, du bois ${ }^{26}$ et des fèves. Saumur remplit une fonction d'entrepôt, pour une grande partie de l'Anjou et du Poitou ${ }^{27}$, comparable à celle qu'exerce Orléans, à une plus grande échelle. En 1779, un article des Affiches de la Touraine et pays Saumurois présente Saumur comme l'entrepôt de "soixante petites villes ou gros bourgs de l'Anjou et du Poitou [...]. La circulation du commerce se fait en grand, et correspond avec la partie méridionale, de même qu'avec le Nord, Paris, Orléans et Nantes. La Hollande et la Flandre y font des provisions considérables de bons vins de Morin, de Coteaux et d'Anjou. Dans les années abondantes, le pays saumurois peut fournir 40000 pièces de vin, 25000 tonneaux de grains, 3500 de fèves, 1550 de pois blancs ou haricots, 250 de maïs ou blé de Turquie. En 1762, il y avait en magasin pour plusieurs millions d'eau de vie ". Dans l'autre sens, "l'entrepôt du Poitou et du Maine se fait en bonne partie à Saumur, pour les épiceries, et beaucoup d'autres marchandises venant des Pays-Bas, et des fers des Pays-Hauts ${ }^{28}$ " [de l'amont].

De grandes quantités de fèves sont expédiées à Nantes. D'après les journaux du péage de la cloison, elles représentent au bureau des Ponts-de-Cé 1155 tonnes en 1753, 673 tonnes en 1761 (période de guerre) et 3072 tonnes en $1766^{29}$ (Annexe 5). Les 3500 tonneaux des « années abondantes » signalés

25. En 1783, le directeur de la régie des aides pour les divisions de Saumur et de Baugé signale les « vins, grains de toute espèces, lins, chanvres, foins et prunes dont il se fait un grand commerce sur les bords de la Loire ". Le Tableau de la Généralité de Tours de 176266 indique que " La Vallée d'Anjou produit beaucoup de prunes qu'on fait cuire " ainsi que " des pruneaux noirs pour teinture ". Il passe chaque année au bureau des traites de Saumur 758760 livres de fruits cuits vers Nantes, et 102900 livres vers Paris. D’après le Dictionnaire universel de la géographie commerçante (an VII), les pruneaux de la vallée de Beaufort " sont recherchés par les Hollandais qui en composent une boisson, dont ils font usage dans leurs équipages, à cause de la propriété antiscorbutique qu'on leur attribue ". La production parait centrée sur les deux rives de la Loire (7 L 194), mais elle s'étend aussi dans la région voisine de Châtellerault et en Touraine. Tableau de la province d'Anjou (1762-1766)..., UzurEau, François Constant (éd.), Angers, Siraudeau, 1901, p. 101 [extrait du Tableau de la généralité de Tours]. Peuchet, Jacques, Dictionnaire universel de la géographie commerçante..., Paris, Blanchon, an VII, tome 2, p. 750 (Beaufort). Arch. dép. de Maine-et-Loire, 7 L 194. Réquisitions, an II. Arch. nat., G 2/30. Mémoire de la Régie des aides, sur la division de Saumur et de Baugé, 1783.

26. Le bois de la forêt royale de Beaufort ainsi que des bois extraits du Baugeois sont utilisés par la Marine (Arch. dép. de Maine-et-Loire, 3L 46. Brion, 19/12/1790. Ibid., C 320. Longué).

27. D’après le Tableau de la généralité de Tours (1762-1766), "On observe que la situation avantageuse de Saumur, entre Orléans, Tours et Nantes, au milieu de la Vallée d'Anjou, rend cette ville très commerçante, et qu'elle sert d'entrepôt de toutes les denrées dont on a parlé précédemment, ce qui rend ses marchés très forts et sa correspondance très active avec Nantes et Orléans ". Le rôle de relais de Saumur se traduit par la présence de nombreuses maisons de commission (Tableau de la province d'Anjou..., UzUREAU, François Constant (ed.), op. cit., p. 105. Arch. nat., F14/1269 et 1270. Enquête sur le commerce et les transports, 1811-1812).

28. UzUREAU, François Constant, "Le commerce et l'Industrie en Anjou (1779) ", L'Anjou historique, 1915-1916, p. 593-597.

29. Merlet, Monique, Le péage..., op. cit., p. 146. - Arch. mun. d'Angers, CC 202. Journaux de 1753 . 
dans l'article de 1779 correspondent à 4390 tonnes $^{30}$. À Nantes, les fèves sont exportées vers l'Espagne, pour la nourriture des mules, ou servent à l'avitaillement des bateaux négriers. Ces navires embarquent couramment 20 à 25 tonnes de fèves destinées à l'alimentation des captifs ${ }^{31}$. Les fèves proviennent de la basse vallée de l'Authion, sur la rive droite de la Loire entre Angers et Saumur ${ }^{32}$, et un peu de Touraine. C'est une culture essentiellement commerciale : la consommation locale, et même régionale, est rare en dehors des périodes de disette.

Il passe aussi aux Ponts-de-Cé, principalement en direction de Nantes, 465 bateaux chargés de tuffeaux du Saumurois en 1753, 404 en 1761, et 416 en 1766. À raison de 25 tonnes par bateau, estimation approximative, cela fait 10000 tonnes par an. Plus à l'ouest, Angers exporte principalement des ardoises. Dans l'échantillon de procès-verbaux, l'ardoise représente 16 chargements sur 22 qui sont partis de cette ville et des Ponts-de-Cé ${ }^{33}$, à destination de Paris, Orléans et Nantes principalement ${ }^{34}$. Il passe aux Pontsde-Cé 2251 tonnes d'ardoises en 1753, 2054 en 1761, et 2581 en $1766^{35}$. Un peu d'ardoise est aussi chargé sur des bateaux à la porte Cupif, au nord d'Angers, probablement à destination du Maine. Dans l'autre sens, Angers reçoit par la Loire des marchandises variées. Un commerce local (céréales, bois, pierres...) existe parallèlement aux échanges avec Nantes ${ }^{36}$. Les tuffeaux et les ardoises livrés à Nantes sont utilisés sur place ou dirigés vers d'autres ports de métropole ou des Antilles ${ }^{37}$.

30. Peuchet, Jacques, Dictionnaire universel..., op. cit., tome 5, « Nantes », p. 205-211. Un tonneau de fèves pèse 2560 livres (1254 kg).

31. Selon le Dictionnaire universel de la géographie commerçante de Peuchet (an VII), les fèves de Beaufort "sont destinées pour la nourriture des nègres et des équipages qui en font la traite, ainsi que pour les mules d'Espagne ". Pour plus de détails, voir BROUARD, Emmanuel et GODELAINE, Florent, « La Loire fleuve "sucré" : voiturage par eau d'une denrée exotique et relations entre bassin fluvial, Nantes et les Antilles aux XVII et XVIII siècles ", Cahiers des anneaux de la Mémoire. La Loire et le commerce atlantique. $X_{\text {XVII }}{ }^{-}$-XIX ${ }^{e}$ siècle, 2015, $\mathrm{n}^{\circ}$ 16, p. 97-98. PEUCHET, Jacques, Dictionnaire universel..., op. cit., tome 2, "Beaufort ", p. 750 .

32. BROUARD, Emmanuel, La société rurale en basse vallée de l'Authion, 1750-1870. Risques économiques, risques environnementaux, crises et mutations dans une vallée peuplée et vulnérable, thèse de doctorat en histoire, université de Poitiers, 2013, p. 83-89 et 111-113.

33. S'ajoutent, depuis Angers, du cidre (1), du cuir (2), du fer (1), et des produits divers (lin, bouteilles, cordes et bougies, pierre tombale).

34. Sur 5 bateaux remontant à Paris, 4 sont chargés d'ardoises. Sur 16 chargements d'ardoises, 4 vont à Paris, 4 à Orléans, 3 à Nantes, les autres à Saumur, Chouzé, Chinon, Tours et Saint-Aignan.

35. MERLET, Monique, Le péage ..., op. cit., p. 183. Arch. mun. d'Angers, CC 202. Journaux de 1753 .

36. Marchandises destinées à Angers. Nantes (9 chargements) : marchandises exotiques, peaux, seigle. Chalonnes (1) : graines de lin. Saint-Florent-le-Vieil (1) : seigle. Châtellerault et Terné (1) : pierres de moulage. Chinon (1) : avoine. Nevers (1) : bouteilles. Rosiers (1) : bois. Beaufort (1) : seigle. Blaison (1) : blé. Gennes (1) : blé. Chênehutte (1) : tuffeau.

37. Sur la place du tuffeau et de l'ardoise dans le commerce avec les Antilles, voir BROUARD, Emmanuel et GodelaINE, Florent, « La Loire fleuve "sucré"... ", art. cit., p. 94-95. Sur le commerce de l'ardoise par cabotage, voir l'étude d'un registre de la traite doma- 


\section{Le Saumurois, le haut Poitou et la vallée d'Anjou fournissent à Nantes de grandes quantités de blé}

L'Anjou et le haut Poitou produisent ordinairement des excédents de blé importants, exportés par la Vienne et la Loire, principalement vers Nantes. En 1802 encore, le préfet Montault Desilles estime que " la consommation du département n'excède pas le produit de ses récoltes, même dans les années où ce produit est médiocre [...] dans les années d'abondance, il existe un excédent sur la consommation annuelle propre à nourrir tous les habitants pendant l'espace d'environ deux mois ${ }^{38}$ ". Ce blé est une des principales marchandises angevines commercialisées par la Loire, et probablement la plus importante. En 1779, l'article des Affiches de la Touraine et pays Saumurois signale l'exportation de 25000 tonneaux de grains du Saumurois, dans les années abondantes. En l'an IX, le maire de Saumur donne une estimation des exportations saumuroises du même ordre de grandeur : 20000 ou 25000 tonneaux par an (22000 à 28000 tonnes) ${ }^{39}$. Ces chiffres sont cohérents avec ceux du bureau des Ponts-de-Cé en 1761 et 1766 : 17670 tonnes et 24745 tonnes environ, en direction de l'aval. En comparaison, les expéditions vers l'amont sont insignifiantes pour ces mêmes années. Par contre, en 1753, année de disette dans le bassin de la Loire, 4076 tonnes de céréales remontent la Loire à Ingrandes, quand seulement 1147 tonnes la descendent aux Pont-de-Cé ${ }^{40}$. Le commerce du blé connaît en effet de fortes fluctuations. La production est irrégulière, tant en volume que dans sa répartition entre seigle et froment. De plus, les importations et les exportations dépendent à la fois du contexte local (prix et production), national ou international, et des freins ou des encouragements de l'État à l'égard du commerce des grains, intérieur et extérieur. Ce commerce des grains suscite une grande méfiance et les autorités changent souvent de politique, pour s'adapter aux circonstances. En temps de disette, il peut engendrer des troubles : la population inquiète bloque la circulation des blés, principalement lors des chargements dans les ports, et souvent impose leur vente ${ }^{41}$. En 1761 encore, année où plus de 17000 tonnes de blé

niale de Nantes de 1720-1722, par Loïc Robin : RoBin, Loïc, Le trafic fluvial en Loire au XVIII siècle en amont de Nantes, d'après les sources nantaises, mémoire de maîtrise, Nantes, 1983 , p. 25.

38. UzUREAU, François Constant, "L'agriculture en Maine-et-Loire ", Anjou Historique, $7^{\mathrm{e}}$ année, 1906 (juillet 1906-mai 1907), p. 645-651. Lettre du préfet du 27/10/1802.

39. Arch. dép. de Maine-et-Loire, 7 L 84. Note de Cochon, maire de Saumur, de l'an IX.

40. Merlet, Monique, Le péage..., op. cit., p. 143. Arch. mun. d'Angers, CC 202. Seigle à la remontée, et froment à la descente. Aucun droit de cloison n'est dû sur les approvisionnements des habitants d'Angers pour leur propre consommation (Arch. mun. d'Angers, HH 29. Sentence de l'élection d'Angers, 19/2/1707).

41. Les 3 émeutes signalées en 1709 sont caractéristiques. Elles ont lieu lors d'embarquement de blé sur des bateaux, aux Ponts-de-Cé, à Angers et à Ingrandes. À chaque fois, des transactions sont conclues entre les autorités et les émeutiers pour que puisse passer une partie du blé (LEHOREAU, René, Cérémonial de l'église d'Angers, 1672-1727. [Analyse par François Lebrun], Paris, C. Klincksieck, 1967, p. 192-193. CHEVALIER, Denis, "Une Chronique Angevine (XVIII " siècle) ", L'Anjou Historique, t. 17, 1916-1917, p. 579. LEBRUN, François, "Les 
descendent la Loire et passent aux Ponts-de-Cé, des attroupements se produisent en Anjou et incitent le roi à faire publier une déclaration rappelant sa position favorable au commerce intérieur du blé ${ }^{42}$.

Les excédents de blé angevins et poitevins sont surtout envoyés à Nantes ${ }^{43}$ et compensent le déficit profond du comté nantais. D'après un état des récoltes de 1784, dans la subdélégation de Nantes, "Les productions en grains [...] ne font ordinairement que du quart au tiers de sa consommation parce que le canton est [en] vignoble [...] elle s'approvisionne pour le surplus des grains des subdélégations voisines et des provinces du Poitou, de l'Anjou, de la Touraine \& autres qui ont presque toujours du superflus quelles envoyent ordinairement à la vente, elle s'approvisionne aussi quelquefois des grains etrangers lorsque les prix y sont (comme cette année dans le Nord) au dessous des grains nationaux ${ }^{44}$ ". Les juges consuls de Nantes, en 1771, formulent des remarques similaires, en ajoutant le Berry et l'Orléanais à la liste des provinces fournissant du blé ${ }^{45}$. La ville dépend fortement du bassin de la Loire pour son approvisionnement, même si d'autres mémoires signalent aussi - quoique moins fréquemment - des importations de blés des ports de Basse Bretagne ${ }^{46}$. Les réexportations à destination des autres provinces sont importantes, en particulier vers la Provence et le Bordelais ${ }^{47}$.

soulèvements populaires à Angers aux XVII ${ }^{\mathrm{e}}$ et XVIII ${ }^{\mathrm{e}}$ siècles ", Actes du $90^{e}$ Congrès national des sociétés savantes, Nice, 1965, Section d'histoire moderne et contemporaine, Tome 1/3, Paris, Bibliothèque nationale, 1966, p. 137. BrouARD, Emmanuel, La société rurale..., op. cit., chapitre III).

42. "Sa majesté ayant esté informée, que dans la disette des bleds qu'il y a en plusieurs de ses Provinces, nottamment en celle d'Anjou : quelques particuliers prennent occasion de s'atrouper tumultueusement avec port d'armes pour empescher le transport desdits bleds de Parroisse en Parroisse \& de Ville en Ville : Ce qui est non seullement contre le secours mutuel, que les Peuples se doivent naturellement pour s'ayder les uns les autres, mais aussi au preiudice du Commerce \& de la tranquilité publique ". La déclaration rappelle aussi, probablement pour rassurer, l'interdiction « de tirer \& sortir de ladite province des bleds, si ce n'est en vertu de Passeport de Sadite Majesté, Signé par l'un de ses Secretaires d'Estat " (Arch. mun. d'Angers, HH 29. 6/9/1761).

43. Sur 36 cargaisons chargées entre La Bohalle et Chouzé (Saumur compris), 28 sont à destination de Nantes, dont 19 des 22 cargaisons de blé. Les 3 autres vont à Angers, Fontevraud et Orléans.

44. Arch. dép. de Loire-Atlantique, C 227. Subdélégation de Nantes. Produit des récoltes au $15 / 9 / 1784$.

45. En 1771, le comté nantais ne fournirait que 6000 à 7000 tonneaux par an pour une consommation de 50 à 60000 . Un mémoire relatif aux récoltes de 1781 dans la subdélégation de Nantes abonde dans le même sens. On prévoit aussi des achats de grains à l'étranger en 1781-1782, notamment en raison des difficultés d'approvisionnement par la Loire entraînées par l'emploi des mariniers dans la Marine royale (Arch. dép. de LoireAtlantique, C 774). Juges et consuls de Nantes en décembre 1771. Observations sur les récoltes de 1781 (le 11/5/1782).

46. Arch. mun. de Nantes, HH 227. Mémoire sur le commerce de Nantes non daté, vers 1700 : importations de céréales de Vannes, Bourgneuf, La Roche-Bernard, Le Croisic, Belle-Île, Noirmoutier, Redon.

47. Le Saumurois joue aussi un rôle important dans l'approvisionnement en blé de la compagnie des Indes à Lorient, par l'intermédiaire de Nantes (LE BoUËDEC, Gérard, " Les 
D'après une lettre de l'intendant de Rennes adressée à celui de Tours, en 1720, "si les habitans estoient privés du secours en grains qui leur viennent du pays haut [de l'amont] ils n'auroient pas de quoy subsister pendant quatre mois ${ }^{48}$ ". L'intendant de Tours s'inquiète, en 1723, d'envois de blé du Saumurois et de Touraine à destination de Nantes. Soupçonnant des exportations illégales vers l'étranger, il demande une enquête pour connaître les besoins précis de Nantes. Un recensement des grains arrivant à Nantes entre janvier 1721 et juin 1723 est réalisé, à partir des comptes du bureau des traites d'Ingrandes à la frontière des " 5 grosses fermes " pour le blé venant d'Anjou, et de ceux de la prévôté de Nantes pour les blés venant de la mer. D'après cette enquête, entre janvier 1721 et la fin juin 1723, sont arrivées à Nantes 11212 tonnes de grains par année depuis l'amont (au total 19726 muids soit 28030 tonnes, froment essentiellement) et 7493 tonnes depuis la mer (14004 muids, seigle surtout). Dans le même temps, 2519 tonnes sont reparties de Nantes. La consommation de la ville et des campagnes voisines étant estimée à 45000 muids, la production locale est probablement de l'ordre de 13041 muids, ce qui correspond à moins du tiers des besoins ${ }^{49}$. Ces quelques chiffres confirment, une fois de plus, la place centrale des " pays hauts " dans l'approvisionnement de Nantes.

La forte prépondérance des envois massifs de blés vers Nantes n'empêche pas des transports plus occasionnels en direction de l'amont. Des débouchés vers Paris sont signalés ${ }^{50}$. De même, lors des disettes, Orléans fait venir des blés de la basse Bretagne (Auray et Vannes), de l'Anjou et du Poitou, notamment en 1693-1694, 1699 et $1709^{51}$. Il arrive aussi, dans les situations critiques, que des blés soient achetés en grande quantité à l'étranger, dans les ports de la Baltique ou aux États-Unis (en 1789), et livrés à Nantes pour approvisionner le bassin de la Loire et au-delà,

approvisionnements de la Compagnie des Indes (1737-1770). L'horizon géographique lorientais ", Histoire, Économie et Société, $3^{\text {e }}$ tr. 1982, p. 377-412).

48. Arch. mun. de Nantes, FF 192. Lettre du 3/9/1720, Debrou intendant de Rennes, à celui de Tours.

49. Ibid., FF 192. États des grains entrés à Nantes et sortis de Nantes, et brouillon d'une lettre adressée le 20 septembre 1723 à l'intendant de Bretagne. Un muid de Paris (ou de Tours) fait 2900 livres de froment environ, ou 2730 de seigle (État des mesures et poids des grains de plusieurs villes de Bretagne, Arch. dép. de Loire-Atlantique, C 227).

50. L'intendant Mirosmesnil signale en 1699 et 1700 que des marchands de Paris et d'Orléans entreposent du blé du Poitou à Saumur, Montsoreau et Cunault. Ils font charger quand une occasion de profit se présente. Correspondance des Contrôleurs généraux des finances avec les intendants des Provinces. Tome deuxième, 1699 à 1708, Boislisle, Arthur Michel de (ed.), Paris, Imprimerie nationale, p. $4\left(\mathrm{n}^{\circ} 13\right)$ et $38\left(n^{\circ} 132\right)$.

51. L'Orléanais est largement excédentaire, la plupart du temps, grâce à la Beauce, mais d'énormes quantités de blés sont prélevées pour Paris (BEAUCORPS, Charles de, L'administration des intendants d'Orléans de 1686 à 1713. Jean de Creil. André Jubert de Bouville. Yves de la Bourdonnaye, Orléans, Marcel Martin, 1911, p. 373-374). 
Paris. C'est le cas en $1693-1694^{52}, 1752-1753,1770^{53}$ et $1789^{54}$. Mais, globalement, les blés en Anjou descendent la Loire bien plus souvent qu'ils ne la remontent.

Les grains exportés par la place de Saumur sont pour partie originaires du Poitou voisin. De grandes quantités de blé arrivent du sud, par la Vienne, par le Thouet, et par la route, passant par le relais des marchés de Loudun, Mirebeau et Richelieu ${ }^{55}$. La vallée d'Anjou, sur la rive droite de la Loire, est aussi grande productrice de blé; il est stocké à Saint-Mathurin et aux Rosiers, avant d'être expédié vers Nantes et vers l'étranger ${ }^{56}$. Dans les procès-verbaux, sur 32 bateaux en provenance de Saumur ou du Saumurois (entre Les Rosiers et Chouzé), 21 chargements sont composés très majoritairement de céréales : du froment complété par du seigle, tous deux chargés en " pagaille ${ }^{57}$ " ou en " poches " (sacs). Plus largement, sur 93 chargements connus à destination de Nantes, 33 , soit plus du tiers, sont composés de céréales.

\section{La Loire, "fleuve de vin"? Une marchandise importante, mais qui est loin de dominer le trafic}

Le faible coût du transport fluvial favorise la culture de la vigne aux abords de la Loire. Au marché intérieur s'ajoute celui des pays du nord

52. Du 1/10/1693 au 29/4/1694, 13892 tonneaux de froment et seigle remontent de Nantes principalement vers Paris (5633 tonneaux), Orléans (3469), Tours (1861) (GABORY, Émile, "La marine et le commerce de Nantes au XVII ${ }^{\mathrm{e}}$ siècle et au commencement du XVIII " Annales de Bretagne, tome XVII, 1902, p. 393).

53. Dans les sept premiers mois de 1770, Nantes a tiré de l'étranger 35655 tonneaux de froment, seigle, orge, fèves et pois (2/3 seigle) (Arch. dép. de Loire-Atlantique, C 775).

54. Ainsi, au printemps 1789 , Orléans réalise des achats importants à Nantes, et surtout, semble-t-il, à Saumur et à Chinon (LEFEBVRE, Georges, Études Orléanaises. T. 2. Subsistances et maximum (1789-An IV), Paris, Commission d'histoire économique et sociale de la Révolution, 1963, p. 8, 14, 15).

55. Arch. nat., G2/30. Régie des aides. Mémoire sur les divisions de Saumur et de Baugé, 1783. Arch. dép. de Maine-et-Loire, 7M 1, Rapports sur l'agriculture, 1835, Saint-Cyr-enBourg et Saint-Just-sur-Dive. Arch. dép. d'Indre-et-Loire, C 337. Enquête de 1746. Arch. dép. d'Indre-et-Loire, C 95. Commerce du blé.

56. Les grains du marché de Beaufort sont envoyés à l'étranger, selon un rapport de 1746 : ils sont stockés à Saint-Mathurin et aux Rosiers puis embarqués pour Nantes. Le Dictionnaire universel de la géographie commerçante (an VII), indique que la vallée de Beaufort " produit abondamment du bled, qui s'enlève pour Nantes et les pays étrangers " (Arch. dép. d'Indre-et-Loire, C 337. Enquête 1746 (Beaufort). PEuCHET, Jacques, Dictionnaire universel..., op. cit., tome 2, p. 750 (Beaufort). Voir aussi : BROUARD, Emmanuel, La société rurale..., op. cit., carte en annexe 11$)$.

57. Arch. dép. de Loire-Atlantique, C 774. Décembre 1771. Objections à l'arrêt du parlement de Rennes du 5/11/1771, par le sieur Beconnais : "Les grains qui arrivent à Nantes dans des batteaux venant sur la Riviere de Loir [sic] et autres adjacentes, et dans des barques et des navires venant sur la mer, sont en pagal ou en vrac, c'est à dire point en sacs; souvent il y en a d'humide qu'on est forcé de faire mettre dans les greniers, sitôt l'arrivée, pour le faire bonnifier. et celui qui arrive sec ni est mis que faute de vente " sur les bateaux où il est d'abord exposé. Mais les procès-verbaux signalent aussi des grains en sacs. 
de l'Europe. Les Hollandais deviennent au début du XvII ${ }^{\mathrm{e}}$ siècle des intermédiaires obligés pour l'exportation des vins blancs de l'Anjou, d'où la présence de " comptoirs " hollandais au Thoureil, aux Ponts-de-Cé et à Chalonnes-sur-Loire, où ils concentrent leurs achats avant de les expédier à Nantes ${ }^{58}$. Cependant, la demande hollandaise diminue à la fin du XVII ${ }^{\mathrm{e}}$ et au XVIII ${ }^{\mathrm{e}}$ siècle. L'ouverture des canaux de Briare (1642) et d'Orléans (1692) entre la Loire et le bassin de la Seine entraîne aussi un basculement des exportations de vins de Loire vers Paris. Dans le Blésois, la rupture est nette en 1642 : le vin, envoyé auparavant massivement à Nantes, est alors envoyé tout aussi massivement vers Paris ${ }^{59}$. Dans le même temps, le commerce du port de Nantes connaît une expansion, notamment avec l'arrivée des marchandises coloniales. De plus les relations avec le pôle orléanais s'intensifient. Ces évolutions réduisent la part relative du vin dans le trafic fluvial en Anjou.

Des droits de douane freinent le commerce du vin de Loire à destination de Nantes. Ils sont perçus à Ingrandes ${ }^{60}$ sur les marchandises circulant entre le territoire des " 5 grosses fermes", dont fait partie l'Anjou, et la Bretagne, province " réputée étrangère " sur le plan douanier. La douane d'Ingrandes est très importante, car c'est là passe, grâce à la Loire, une grande partie des produits qui circulent entre la Bretagne et les provinces de l'intérieur ${ }^{61}$. Selon Véron de Forbonnais (1758), La Bretagne " gagne considérablement à rester dans l'état où elle est à cause de ses vins \& eaux-de-vie. Plus on a chargé [d'impôts] les vins \& eaux-de-vie d'Anjou, plus les péages \& les droits infinis perçus sur la Loire ont renchéri les denrées des cinq grosses fermes \& plus celles de Bretagne ont eu d'avantage ${ }^{62}$ ". Á Nantes, les vins de Loire de qualité courante sont donc désavantagés

58. MANASSE, Vivianne, Le comptoir hollandais du Thoureil, Conseil général de Maine-etLoire, 2003, 4 p. FraYsSE, Jean et Camille, Loire Angevine et Maine : mariniers et riverains d'autrefois, Cholet, Farré et fils, 1967, p. 34.

59. Person, Françoise de, Les voituriers par eau et le commerce sur la Loire à Blois au XVIT siècle, thèse de $3^{\mathrm{e}}$ cycle, Université de Tours, 1984, p. 206-217.

60. Sur la douane d'Ingrandes : MARÉCHAL, Paul, "À la frontière de Bretagne : Ingrandes aux XVII ${ }^{\mathrm{e}}$-XVIII ${ }^{\mathrm{e}}$ siècles ", L'information historique, 1966, $\mathrm{n}^{\circ} 1$, p. 37-41; $\mathrm{n}^{\circ} 2$, p. 85-87; $\mathrm{n}^{\circ} 3$, p. 133-135; $\mathrm{n}^{\circ} 4$, p. 176-178. Dion, Roger, Histoire de la vigne et du vin en France des origines au XIX siècle, Paris, 1959, p. 448-458.

61. Un lent processus d'unification douanière conduit au regroupement de nombreuses provinces du centre de la France dans les " cinq grosses fermes ", en référence à l'affermage d'une partie des impôts indirects. On y trouve l'Île de France, l'Anjou, l'Aunis, le Beaujolais, le Berry, le Boulonnais, la Bourgogne, la Champagne, le Bourbonnais, le Maine, la Normandie, la Touraine, etc. Font partie des provinces réputées étrangères : la Bretagne, l'Auvergne, l'Artois, l'Angoumois, la Flandre, la Lorraine, le Lyonnais, la Saintonge, le Roussillon... Colbert impose en 1664 puis en 1667 un tarif commun applicable sur les frontières extérieures, mais échoue à faire entrer les provinces " réputées étrangères " [au tarif de 1664] dans le périmètre des 5 grosses fermes (Boy, Jean-Claude, L'administration des douanes en France sous l'Ancien régime, Neuilly-sur-Seine, Association pour l'histoire de l'administration des douanes, 1976, p. 11-29).

62. VÉRON DUVERGER DE FORBONNAIS, François, Recherches et considérations sur les finances de France depuis l'année 1595 jusqu'à l'année 1721. Tome premier..., Basle, frères Cramer, 1758, p. 369. 
vis-à-vis des vins nantais; seuls ceux dont la valeur est relativement élevée peuvent passer la douane d'Ingrandes, car la part des droits dans le prix final est alors plus faible, ces droits étant perçus au volume, et non à la valeur. Mais en Anjou, les vignobles de qualité situés près de la Loire, produisent moins que ceux de qualité médiocre dont les vins sont destinés à la consommation intérieure ${ }^{63}$. Des obstacles sont aussi mis à l'expédition des vins d'" amont " dans les colonies. Plusieurs arrêts, dont le plus connu est celui de 1717, ont déchargé des droits de sortie les marchandises envoyées aux Antilles mais un arrêt du 10 mai 1723 impose pourtant, pour les vins de Loire destinés aux Îles, le paiement de tous les droits de sortie des " 5 grosses fermes ». D'après une supplique du maire et des échevins de Tours adressée au Conseil en 1785, cette restriction aurait été imposée " sous le prétexte que les vins de la Loire ne sont pas propres aux passages de la mer [...]. Cette perception énorme [... équivaut pour les Provinces de la Loire à une prohibition absolue de passage ${ }^{64}$ ". Le texte de l'arrêt justifie cette mesure par l'introduction en fraude de vins de Loire en Bretagne, sous prétexte de les conduire aux Îles. Quoi qu'il en soit, cette mesure explique la prédominance des vins nantais et bordelais dans les exportations de Nantes vers les Antilles ${ }^{65}$. Plus largement, la politique douanière désavantage les vins de Loire et favorise la production nantaise, au point que des mesures sont prises pour interdire les plantations de vignes, afin de maintenir une production locale de blé66.

Il est possible d'évaluer approximativement les volumes de vin circulant sur la Loire en Anjou. D’après le Tableau de la généralité de Tours (17621766), l'Anjou envoie 18000 pièces de vin vers Nantes (4122 tonnes net ${ }^{67}$ ), et 34000 pièces vers Paris (7786 tonnes) ${ }^{68}$. Les vins blancs de haut cru, les

63. Les meilleurs vins du Saumurois sont ceux du coteau, et en Layon, ceux de la région proche de la confluence avec la Loire (Chalonnes, St Aubin-de-Luigné, Rochefort, Thouarcé...). En amont, sur le Layon, et au sud du Saumurois, la qualité baisse. RENOU, Michel, Les pressoirs..., op. cit., p. 57.

64. Merlet, Monique, Le péage..., op. cit., p. 131. Cette réputation des vins de Loire de mal se conserver en mer se voit dans un traité des vivres pour les vaisseaux de 1776 : les vins d'Anjou et de Touraine peuvent être distribués aux équipages pendant les séjours dans les ports et les rades, mais on doit acheter des vins de Bordeaux pour les périodes en mer (Encyclopédie méthodique. Marine. T. 2, Paris, Panckoucke, 1786, p. 26. Extrait du Traité des vivres pour les vaisseaux \& autres bâtiments de sa majesté, de Claude Fay, 13 février 1776).

65. Entre 1750 et 1755, Nantes envoie chaque année de 309 à 736 tonneaux de vin nantais aux Îles, de 183 à 654 tonneaux de vins de Bordeaux, et à peine quelques barriques de vins « d'amont ". Le vin nantais disparait sur ce marché après la guerre de Sept Ans (Arch. dép. de Loire-Atlantique, C 716 et C 717).

66. Le 13 avril 1701, M. De Nointel, intendant en Bretagne, au contrôleur général (BoIsLisle, Correspondance..., op. cit., $\mathrm{n}^{\circ} 258$ ).

67 . Ces " pièces " sont des busses de vin de 240 pintes, soit autour de 229 litres.

68. "Les vins qu'on exporte pour Paris ou pour l'étranger, proviennent des côtes du Layon, de Savennières, de Soulaines et de Trélazé. ". Les exportations pour l'étranger par Nantes sont estimées à 10000 pièces, et celles pour Paris à 4000 pièces. À cela s'ajoute la production du Saumurois : 8000 pièces de vins blancs de première qualité pour Nantes, 
plus estimés des courtiers hollandais, sont enlevés pour la mer. Les vins rouges sont envoyés à Angers et dans le Bas-Maine. Les vins médiocres sont destinés à Orléans et à Paris ${ }^{69}$. À ces vins d'Anjou envoyés à Nantes s'ajoutent des vins de la Touraine et du Blésois, bien que ces provinces soient tournées principalement vers Paris ${ }^{70}$.

Voyons maintenant les données fournies par les journaux de la cloison d'Angers. Les quantités relevées au bureau des Ponts-de-Cé, où passent les marchandises à la descente et celles qui empruntent le pont, sont de 43016 busses et poinçons de vin en 1753 (environ 9893 tonnes, poids net), 23600 busses de vin en 1761 (5428 tonnes) et 36414 busses en 1766 (8375 tonnes) (Annexe 5). Cependant, une partie des vins taxés aux Pontsde-Cé à destination d'Angers et du Maine n'emprunte pas la Loire mais franchit les ponts sur des charrettes. Enfin, les vins tirés de leurs domaines par les catégories aisées de la ville ne sont pas taxés, mais cela ne représente que des volumes limités. Dans l'autre sens, les quantités à la remonte arrivant de Bretagne au bureau d'Ingrandes sont négligeables. À cela s'ajoutent les vins passant au bureau de La Pointe, à la confluence de la Loire et de la Maine, et essentiellement destinés à la province du Maine. Ces vins viennent de la zone entre Ingrandes et les Ponts-de-Cé, qui inclut notamment les vignobles de Savennières et de Chalonnes, ainsi que la confluence du Layon et de la Loire. Ils représentent 811 tonnes en 1753, 2698 tonnes en 1761, et 764 tonnes en 1766. Sur l'ensemble de la Loire, le gros du trafic est donc orienté vers Nantes et Angers. En 1753, 52,3\% du vin passé aux Pontsde-Cé est destiné à Nantes (5176 tonnes), 28,9 \% à Angers (2858 tonnes), et $4,2 \%$ au Maine (413 tonnes) ${ }^{71}$. Cependant, pour leur grande majorité les vins envoyés vers Angers sont probablement eux aussi destinés au Maine ${ }^{72}$. Le vin est une des principales marchandises circulant sur la Mayenne au XVIII ${ }^{\mathrm{e}}$ siècle : d'après les comptes du droit de " navige ", environ 2000 tonnes de vin remontent chaque année vers Laval ${ }^{73}$.

L'importance du volume de vin passant à La Pointe en 1761 pourrait être liée à une réorientation des vins de la région de Savennières et du

et 30000 pièces de vins blancs de seconde qualité pour Paris, par la Loire également (Tableau de la province d'Anjou..., op. cit., UzuREAU, François Constant (éd.), p. 99).

69. Arch. nat., G 2/30. Mémoire de la Régie des aides, sur la division de Saumur et de Baugé, 1783.

70. Les vins du Blésois et de l'Orléanais sont ordinairement décrits comme tournés résolument vers la capitale, mais les journaux de la cloison de 1753 mentionnent de nombreux Blésois voiturant des vins (Arch. mun. d'Angers, CC 202. Journaux de la cloison de 1753).

71. Monique Merlet estime pour sa part qu'en 1761 la moitié du vin va à Nantes et l'autre moitié à Angers. En 1766, le rapport serait des $3 / 4$ et de 1/4. Cependant, elle ne semble pas avoir effectué de calcul précis.

72. De plus, $1,98 \%$ du vin est dirigé vers " Nantes et Angers ", et 6,46\% a une destination inconnue.

73. Plus ou moins 5000 pipes par an selon les époques, soit 10000 busses de 230 litres. 8000 busses seulement dans la dernière décennie de l'Ancien Régime d'après un mémoire de 1792 (Roussier, Paul, Notes historiques sur la rivière de Maine ou Mayenne et sa navigation, Laval, Goupil, 1924, p. 164). 
Layon vers le Maine, en raison des difficultés du commerce nantais liées à la guerre. Pourtant, le port de Nantes exporte en 1761 une grande quantité de vin d'amont : 7433,5 tonneaux, contre 5340,7 en 1753, et 4010 en 1766; elle est supérieure à ce qui passe au bureau des Ponts-de-Cé. Peut-être les entrepôts nantais sont-ils encombrés de vins d'amont accumulés depuis le début de la guerre. Pour 15 années entre 1751 et 1776, la moyenne des exportations de vins d'amont est de 3720 tonnes; ces vins sont expédiés à 93 \% vers la Flandre autrichienne (Belgique) et la Hollande. Les vins franchissant la frontière de Bretagne sont donc en grande partie exportés à l'étranger. Á cela s'ajoute la consommation bretonne. D'après la supplique de 1785 du maire et des échevins de Tours, les vins de la Loire qui s'expédient en Bretagne n'excèdent pas 10000 muids, soit environ 2740 tonnes $^{74}$.

\section{Trafic du vin sur la Loire angevine et la Maine au XVIII siècle}

\begin{tabular}{|l|c|c|c|c|c|}
\hline \multirow{2}{*}{ Années } & \multicolumn{2}{|c|}{ Bureaux du péage de la cloison } & \multirow{2}{*}{ Pour la } \\
\cline { 2 - 4 } & $\begin{array}{c}\text { Ponts-de-Cé. } \\
\text { Par terre et } \\
\text { par eau }\end{array}$ & Ingrandes & $\begin{array}{c}\text { La } \\
\text { Pointe }\end{array}$ & $\begin{array}{c}\text { Exportation } \\
\text { de vins } \\
\text { d'amont au } \\
\text { départ de } \\
\text { Nantes }\end{array}$ \\
\hline 1753 & $\begin{array}{c}9893 \text { tonnes } \\
(1 / 2 \text { vers } \\
\text { Nantes, } 1 / 3 \\
\text { Angers) }\end{array}$ & 229,2 tonnes & $\begin{array}{c}811 \text { tonnes } \\
\text { (vers le } \\
\text { Maine) }\end{array}$ & - & $\begin{array}{c}5340,7 \\
\text { tonnes }\end{array}$ \\
\hline \begin{tabular}{l|c|c|c|c|}
1761 \\
(guerre)
\end{tabular} & 5380 tonnes & 380 tonnes & 2698 tonnes & - & $\begin{array}{c}7433,5 \\
\text { tonnes }\end{array}$ \\
\hline 1766 & 8302 tonnes & 85 tonnes & 764 tonnes & - & 4010 tonnes \\
\hline 1751 à 1776 & - & - & - & - & $\begin{array}{c}3720 \\
\text { tonnes/an } \\
\text { (moyenne) }\end{array}$ \\
\hline 1785 & - & - & - & 2740 tonnes & - \\
\hline
\end{tabular}

Sources :

- Cloison : Arch. mun. d'Angers, CC 202 (1753), CC 30 (1761), 31 et 32 (1766). Étude par Monique Merlet pour 1761 et 1766. - MerLet, Monique, Le péage..., p. 122 et 127.

- Exportation de vin d'amont : - Archives dép. de Loire-Atlantique, C 716 (1749-1764), C 717 (17651779). Traites foraines.

- Envois en Bretagne, 1785 : Merlet, Monique, Le péage..., op. cit., p. 131.

Ces chiffres sont cohérents avec les 4104 tonneaux de vin du Saumurois dirigés vers Nantes signalés dans le Tableau de la généralité de Tours, sachant que des vins de Touraine et du Blésois accompagnent les vins

74. Merlet, Monique, Le péage..., op. cit., p. 131. Supplique des maire et échevins de Tours de 1785. Il s'agit très vraisemblablement du vin destiné à la consommation de la province, sans comprendre les exportations vers le nord de l'Europe, mais ce n'est pas explicité. Monique Merlet considère qu'un muid correspond à un tonneau et fait 4 busses, mais le muid parfois utilisé pour le vin en vallée de la Loire, notamment dans les pancartes des péages, est le muid de Paris, de 274 litres, soit 1,2 busse. 
d'Anjou. L'année 1753 paraît exceptionnelle. On peut donc estimer entre 5000 et 10000 tonnes le trafic sur la Loire et sur les ponts, à destination principalement de Nantes et du Maine. Pour déterminer précisément la part du transport par charrettes sur les ponts, provenant de la rive sud de la Loire (Saint-Jean-des-Mauvrets, Juigné, Mûrs-Érigné, etc.), de l'Aubance et peut-être d'une partie du Layon, il faudrait repérer les voituriers par terre parmi l'ensemble des voituriers se présentant au bureau des Ponts-de-Cé. Un ordre de grandeur de 2000 à 2500 tonnes me parait vraisemblable.

Le vin occupe donc dans le trafic une place importante, mais inférieure habituellement à celles du blé, du sel et du bois. L'image communément répandue de la Loire " fleuve de vin ${ }^{75}$ " s'appliquerait mieux à la Loire orléanaise et à la haute Loire, où le vin représente une part importante des chargements dirigés vers Paris ${ }^{76}$. Abel Poitrineau a étudié les comptes du péage de Myennes situé près de Cosne (Nièvre), pour 1733. Il relève 165000 hectolitres de vin (16500 tonnes) sur un trafic total qu'il estime entre 50000 et 100000 tonnes, soit entre 16 et $32 \%$ du volume ${ }^{77}$. Une nouvelle étude détaillée de ce péage permettrait des comparaisons fructueuses entre les trafics sur la haute Loire et ceux sur la Loire angevine.

\section{Au delà de l'Anjou, Nantes s'approvisionne aussi dans tout le bassin de la Loire - importance du bois}

Plaçons-nous maintenant du point de vue nantais. L'aire d'approvisionnement de Nantes est très large. 99 procès-verbaux concernent des bateaux chargés pour cette destination ${ }^{78}$, et dans 86 d'entre eux le lieu de chargement est indiqué. L'Anjou domine, envoyant beaucoup de blé à Nantes, comme cela a déjà été dit. Orléans vient en seconde position avec 17 chargements très variés (farines, blé, chanvre, vin, bois, armes, etc.) ${ }^{79}$, puis Tours en troisième position, avec 7 chargements (ocre, cuir, draperies, confitures, pruneaux, bois, draps). De la Vienne en amont de Chinon, et plus particulièrement de Châtellerault (6) et de ses environs (Terné, Chitré),

75. Cette image tient peut-être en partie à l'attention portée à ce produit pour des raisons culturelles et commerciales. De plus, les liens historiques entre le vin et les transports par eau étant connus de longue date, la tentation est grande de surestimer la place du vin dans le commerce fluvial. Enfin, le trafic a été davantage étudié en haute Loire et Loire moyenne, où la place du vin est plus importante qu'en basse Loire.

76. Voir aussi les travaux de Françoise de Person sur le Blésois.

77. PoITRINEAU, Abel, et autres, « Du volume, de la consistance et des variations conjoncturelles saisonnières du trafic sur la Loire à partir des péages et des papiers notariaux ", dans Quand l'Allier portait bateau : table ronde de l'Institut d'Études du Massif Central, InSTITUT D'ÉTUDES DU MASSIF CENTRAL (éd.), Clermont-Ferrand, Faculté des Lettres et Sciences humaines, 1989, p. 42.

78. Dans deux cas seulement, des arrêts sont prévus sur le trajet, à Angers et au Marillais.

79. 11 chargements connus sur 17 partis d'Orléans, et presque tous destinés à Nantes : farine (1), blé et farine (1), froment (1), orge (1), farine et bois de chauffage (1), bois merrain (1), sirop (1), vin (1), chanvre (1), meubles (1), poudre à canon (1), armes et fromages (1), couvertures, bonnets de laine, draps, vin du Levant, confiture (1). 
viennent 8 chargements, dont 5 de froment à destination de Nantes (avec un ajout de coutellerie), et 3 de " pierre de moulages " (meules à grains) pour Angers et Chalonnes ${ }^{80}$. Trois chargements proviennent du Cher, transportant du bois de Vierzon (deux trains) et du fer de Saint-Aignan, avec un peu de vin. Ces chargements concordent avec les descriptions du temps ${ }^{81}$. Enfin, de la haute Loire et de l'Allier partent vers Nantes du bois, du charbon, du fer, et de la faïence ${ }^{82}$. Les quantités paraissent relativement limitées, car les bateaux chargés en ces pays de houille, de vin, de bois, de produits du Midi et du Lyonnais ${ }^{83}$, s'arrêtent majoritairement à Orléans ou prennent le canal de Briare vers Paris.

Dans les procès-verbaux, le bois est la seconde marchandise destinée à Nantes après le blé. Il représente 13 des 93 chargements connus, venant surtout de la haute Loire et de l'Allier, mais aussi de Tours, de Chinon, de la région du Mans, et de Vierzon sur le Cher. Il est soit chargé sur des bateaux, soit assemblé en "échargeaux " (radeaux). Les journaux de la cloison d'Angers font ressortir encore plus nettement l'importance du bois. En 1753, 9078 charretées de bois transitent par le bureau des Ponts-de-Cé, principalement à destination de Nantes. Si l'on prend comme repère la valeur d'une charretée de bois dans le Maine, cela correspond approxima-

80. D’après Creuzé-Latouche (1790) à Châtellerault « les seuls objets d'exportation par la Vienne sont des eaux de vie de la Saintonge, quelques fruits secs du pays, des grains provenant des pays voisins, \& des meules de meulières. Les objets d'importation sont du fer, du charbon de terre, de la résine, de l'ardoise, de la potterie, de la fayance, objets qui viennent du Berry, par le Cher, du Nivernois, de l'Orléanois \& de l'Anjou par la Loire ». Il signale aussi l'importance de la coutellerie à Châtellerault. Une partie des importations, notamment les faïences et poteries, sont réexpédiées en haut Poitou. On retrouve dans les procès-verbaux les grains et meules, mais pas les eaux-de-vie. Il est vrai que l'échantillon est réduit. De plus, Creuzé-Latouche signale un report des eaux-de-vie vers le transport routier. Par ailleurs, Geneviève Cerisier-Millet a étudié le commerce de Châtellerault, en particulier à travers les Affiches du Poitou de 1776 à 1780. Ce journal publie une fois par mois le nombre de bateaux entrant au port ou en sortant, et leurs marchandises : les principales au départ de Châtellerault sont le blé, l'eau-de-vie (pour Paris), les pierres de moulage et les pruneaux. Elle a aussi retrouvé ces marchandises dans des procès-verbaux d'avaries sur la Vienne (CREuzé-LATOuche, Jacques-Antoine, Description topographique du district de Chatelleraud, département de la Vienne..., Châtellerault, P.J.B. Guimbert, 1790, p. 26 à 29. CERISIER-MILLET, Geneviève, Les mariniers de la Vienne et de la Loire aux XVII e et XIX $X^{e}$ siècles : Châtellerault port d'attache, La Crèche, Geste, 2010, p. 140-153, et annexe 6 (avaries).

81. D’après un mémoire des entrepreneurs de la voiture du sel (après 1785), la navigation se fait jusqu'à Vierzon. "Il n'y a que les sels pour la fourniture des greniers du Berry qui remontent dans cette rivière, il en descend du mairain [du bois destiné aux tonneaux notamment] en assez grande quantité, des fer et de l'ocre pour Nantes " (Arch. nat., G 1/97).

82. Marchandises de la haute Loire et de l'Allier : Moulins : 1 train de bois, vers Nantes. Nevers : faïence 2 chargements (Nantes), bouteilles (Angers). Roanne : charbon de terre 1 (Nantes). Cosne : fer 1 (Nantes). Saint-Satur : terre jaune 1 (Nantes). Diou : échargeaux de bois 2, bois de marine en bateau 1 (Nantes).

83. Poitrineau, Abel, "La Loire marchande, les trafics d'antan ", dans VigiER, Philippe (dir.), Une histoire de la Loire, Paris, Ramsay, 1986, p. 93. 
tivement à 24058 tonnes $^{84}$. À cela s'ajoutent 2872 tonnes de bois merrain destiné principalement à la fabrication de barriques, 2204 tonnes de tan, et 370 tonnes de lattes. Dans le même temps, 19841 tonnes de bois arrivent en onze mois à Angers, au bureau de la Haute Chaine, en descendant la Maine (Annexe 6). Le bois, pourtant peu présent dans les dossiers de l'administration et de la Chambre de commerce de Nantes, apparaît ici comme la principale marchandise, en volume, transportée sur la Loire.

En 1761 et 1766, les quantités de bois déclarées s'effondrent à 4614 tonnes et 7460 tonnes. Le merrain reste important avec 3492 et 1156 tonnes $^{85}$ (Annexe 5). Le recul est moindre à la Haute Chaîne, mais le bois diminue quand même d'un tiers. Cette évolution tient peut-être en partie aux fluctuations des approvisionnements de la marine royale. D'après David Plouviez, la reconstruction de la flotte dans les années 1750 « exploite de façon inédite et unique au XVIII ${ }^{\mathrm{e}}$ siècle les provinces françaises ". Pendant cette période de " grand stress forestier ", le bassin de la Loire est largement mis à contribution. Le mouvement s'interrompt brutalement vers 1760 , avant de repartir par la suite ${ }^{86}$. Malgré le recul observé en 1761 et 1766 , le bois reste une des principales marchandises transportées sur la Loire. Au bois transporté en radeaux et sur les bateaux, il faut ajouter celui dont ces derniers sont constitués. Le trafic descendant domine largement, d'où un marché important des bateaux d'occasion en basse Loire, et des démantèlements destinés à fournir des matériaux de construction, voire du bois de chauffage ${ }^{87}$.

\section{De Nantes remontent du sel, du poisson, des marchandises du Midi et de plus en plus, des colonies}

Les marchandises remontant la Loire depuis Nantes sont très variées : sur les bateaux prennent place du sel, des poissons, des marchandises coloniales (sucre, café, bois tinctoriaux...), des produits du sud de la France (huile d'olive, savon), et des céréales lors de disettes. À la veille de la Révolution, ce sont plus de 13000 tonnes de sel qui sont embarquées à Nantes pour être livrées dans les divers greniers à sel du bassin de la Loire ${ }^{88}$. Et pourtant, le sel est nettement sous-représenté par les procèsverbaux (cf. ci-dessus). Les céréales, pour leur part, ne représentent que

84. En Mayenne et en Sarthe, une charretée de bois de chauffage fait respectivement 3,12 et 3,5 stères. Le poids du chêne et du hêtre est de $800 \mathrm{~kg} / \mathrm{stère}$. Donc 1 charretée pèse entre 2496 et $2800 \mathrm{~kg}$ dans le Maine. Moyenne de $2650 \mathrm{~kg}$ utilisée ici (Arch. mun. d'Angers, C 202. Journaux de la cloison d'Angers, 1753. CHARBOnNIER, Pierre et PoITRINEAU, Abel, Les anciennes mesures locales du centre-Ouest : d'après les tables de conversion, Clermont-Ferrand, Presses universitaires Blaise-Pascal, 2001, p. 144 et 158).

85. MERLET, Monique, Le péage..., op. cit., p. 172.

86. PlouvIEZ, David, La marine française et ses réseaux économiques au XVII siècle, Paris, Les Indes savantes, 2014, p. 185.

87. BRouARD, Emmanuel, "La navigation en Loire au XVIII ${ }^{\mathrm{e}}$ siècle... ", art. cit., p. 38-39.

88. Arch. nat., G1/97. 1788. Comptes de l'entreprise de la voiture des sels, $2^{\mathrm{e}}$ année du bail de Mager. 
4 chargements remontant sur 93 . On est loin des 33 chargements de grains descendant vers Nantes. Sur ces 4 chargements, 3 correspondent à des années de disette dans le val de Loire : 1751, 1753 et 1770; ces années-là, Nantes importe de l'étranger de grandes quantités de blé ${ }^{89}$.

Si le sel et les céréales représentent des chargements homogènes, d'autres marchandises sont associées pour former des ensembles très hétéroclites : un même bateau peut transporter sucre, café, poisson, huiles, savon, riz, citrons, indigo et peaux tannées. Un tableau (Annexe 2) recense les apparitions, dans les procès-verbaux, des produits remontant de Nantes, ainsi que les cas où ils représentent tout le chargement ou presque (au moins 95 \% du volume). Le sucre domine parmi ces marchandises remontantes : sur 92 bateaux chargés à Nantes, 43 portent du sucre, (46,7 \% des bateaux chargés à Nantes, ou 32,8 \% du total des bateaux remontant). Le sucre représente la seule marchandise, ou au moins les $9 / 10^{\mathrm{e}}$ du chargement, dans 17 cas et dans 26 autres, il est associé à d'autres produits. Il constitue probablement de 25 à $30 \%$ du total des marchandises remontant de Nantes selon ces procès-verbaux. Cette part est très importante, même s'il faut garder à l'esprit que le sel est sous-représenté. On recense aussi de grandes quantités de poissons (27 occurrences, dont 5 chargements complets), du café (14 occurrences), de l'huile (13), du bois des Indes (8), du cacao (5). Les quantités sont très variables selon les produits. Ainsi, le café ne représente généralement que quelques balles, barils ou barriques.

Le sucre occupe au XVIII ${ }^{\mathrm{e}}$ siècle une place croissante dans le trafic sur la Loire en direction de l'amont. Nantes est alors un des principaux ports français pour le commerce avec les Antilles ${ }^{90}$. Le sucre brut, importé en grandes quantités, est majoritairement réexporté par la mer mais il est aussi diffusé dans le val de Loire où s'affirme une industrie sucrière. Des raffineries s'implantent à Nantes, puis à Angers, Saumur et surtout à Orléans où sont produits les deux tiers du sucre raffiné du royaume, principalement pour alimenter Paris ${ }^{91}$. Les raffineries orléanaises passent de 3 en 1698 à 14 en 1775 et 23 en $1785^{92}$. Elles utilisent comme matières premières des

89. Respectivement 9934 tonnes de céréales, 11620 tonnes (dont 4076 remontent la Loire) et 40707 tonnes. Ce sont des années exceptionnelles, car les deux tiers du temps, entre 1751 et 1776, les importations de l'étranger sont nulles ou inférieures à 1000 tonnes (Archives dép. de Loire-Atlantique, C 716 et C 717).

90. PÉTRÉ-GRENoUILLEAU, Olivier, Les négoces maritimes français XVII -XXe siècle, Paris, Belin, 1997, p. 120.

91. Plusieurs travaux vont permettre de mieux connaitre la place du sucre dans le commerce et l'économie du bassin de la Loire. Maud Villeret a soutenu en novembre 2015 à Nantes une thèse en histoire intitulée Le goût de l'or blanc. Transformation et diffusion du sucre dans la vallée ligérienne au XVIII ${ }^{e}$ siècle. Gaëlle Caillet prépare à Paris 1 une thèse en archéologie, ayant pour titre provisoire Archéologie du sucre de canne : les raffineries de sucre du Val de Loire, XVII ${ }^{e}$-XIX ${ }^{e}$ siècles.

92. Dion, Roger, "Orléans et l'ancienne navigation de la Loire ", Annales de Géographie, tome $47, \mathrm{n}^{\circ} 266,1938$, p. $142-143$. 
sucres bruts et terrés ${ }^{93}$ acheminés depuis Nantes par la Loire. L'essor de ces établissements entraîne donc celui du transport du sucre.

D'après diverses sources (tableau suivant), les raffineurs orléanais produisent dans les années 1770 entre 6 et 8 millions de livres de sucre blanc (3400 tonnes), 11 millions en 1785 (5500 tonnes), 13 ou 16 millions en 1790 (6370 ou 7840 tonnes). Il est possible d'estimer les matières premières remontant la Loire en se basant sur la production finale de sucre raffiné à Orléans ${ }^{94}$. D'après de nombreux mémoires du XVIII ${ }^{\mathrm{e}}$ siècle, il faut 225 livres de sucre brut pour produire 100 livres de sucre raffiné. D'autres mémoires indiquent une proportion de 150 livres de sucre terré pour faire 100 livres de sucre raffiné ${ }^{95}$. Concrètement, on utilise souvent un mélange de sucre brut et de sucre terré, dans des proportions variables selon les auteurs, les circonstances et les entreprises, mais avec une majorité de sucres bruts ou " moscouades ${ }^{96}$ ". Un rapport de 170 livres de matières premières (sucre brut et terré) pour 100 livres de sucre raffiné paraît une bonne approximation. En l'appliquant aux données dont on dispose sur la production orléanaise, on arrive à une importation de 5780 tonnes de matière première par an environ dans les années 1770, et de 10000 à 13000 tonnes à la fin de l'Ancien régime. On sait aussi, grâce aux comptes annuels d'un receveur des traites à Ingrandes, qu'il remonte un peu moins de 2000 tonnes de sucre par an pendant le premier quart du siècle ${ }^{97}$. Enfin, d'après les journaux du péage de la cloison d'Angers, il passe environ 4043 tonnes de sucre en

93. Le sucre terré est un sucre sommairement préparé au regard du sucre " raffiné ", mais suffisamment en tout cas pour être consommé tel quel. Il entre aussi dans la fabrication du sucre raffiné. Le terrage du sucre permet aux colons des Îles de transformer une partie de leurs sucres bruts, à défaut de pouvoir établir de nouvelles raffineries, l'État s'y opposant afin de préserver les intérêts des raffineurs de métropole.

94. J'ai déjà abordé ce point dans un article récent. Des recherches effectuées depuis m'ont conduit à réévaluer le rapport entre matières premières et sucres raffinés de 200 pour 100 à 170 pour 100. BRouARD, Emmanuel et Godelaine, Florent, "La Loire fleuve "sucré"..." ", art. cit., p. 92-93.

95. Arch. dép. de Loire-Atlantique, C 730. Ibid., C 733. Ibid., C 700.

96. Ainsi, un état général des raffineries de 1795-1796 évalue la consommation annuelle de 24 raffineries " en pleine activité " à 18550000 livres de sucre brut, et 3385000 livres de sucre terré, soit au total 10750 tonnes. L'inspecteur des manufactures Tribert écrit en 1790, qu' " en général on emploie [...] 150 livres de sucre brut et 50 livres de sucre terré pour obtenir 125 livres de sucre raffiné ". Enfin, un mémoire des raffineurs d'Orléans, vers 1787, indique une proportion de 100 livres de sucre brut et 83 livres de sucre terré pour produire 100 livres de sucre raffiné (Arch. nat., F12/1502. s.d.) (1795-1796 d'après Gaëlle Caillet). Ibid., F12/562. Mémoire de Tribert, inspecteur des manufactures, vers 1790. Ibid., F12/1639A. Mémoire des entrepreneurs des manufactures de sucre, s.d. (1787 d'après Gaëlle Caillet).

97. 1972 tonnes de sucre brut et terré en 1711, puis en moyenne 1849 tonnes par an de 1717 à 1726 d'après les comptes rendus de Jean Chesnard, receveur des droits au bureau d'Ingrandes. Une partie des droits d'entrée dans les " 5 grosses fermes " est reversée aux fermiers du "Domaine d'occident ". Cette ferme a été maintenue après la suppression de la compagnie des Indes en 1674. Les rapports annuels paraissent liés à ce partage des recettes. Loïc Robin a étudié les comptes des années 1717-1726 (Archives dép. de Loire-Atlantique, C 855. RoBIn, Loïc, Le trafic fluvial en Loire..., op. cit., p. 57-62). 
Quel commerce fluvial en Loire angevine au XVIII ${ }^{\mathrm{e}}$ siècle?

\section{Évaluations des quantités de sucre remontant la Loire au XVII' siècle}

\begin{tabular}{|c|c|c|c|}
\hline & $\begin{array}{l}\text { Production de sucre raf- } \\
\text { finé à Orléans } \\
\text { Millions de livres, ou tonnes }\end{array}$ & $\begin{array}{l}\text { Importation de sucres } \\
\text { bruts et terrés à } \\
\text { Orléans } \\
\text { < déduction à partir du } \\
\text { sucre raffiné, } \\
\text { ou données directes > }\end{array}$ & $\begin{array}{l}\text { Sucres passant } \\
\text { au bureau } \\
\text { d'Ingrandes }\end{array}$ \\
\hline 1697 & & 624,6 tonnes & \\
\hline 1711 & & & 1972 tonnes \\
\hline 1714 & & $\begin{array}{l}1995 \text { tonnes }(+ \text { Angers } 342 \\
\text { tonnes, Saumur } 342)\end{array}$ & \\
\hline 1717 à 1726 & & & 1849 tonnes /an \\
\hline 1744 & & 2450 tonnes & \\
\hline 1753 & & & 4043 tonnes \\
\hline 1761 (guerre) & & & $\begin{array}{l}240 \text { tonnes } \\
\text { [Guerre] }\end{array}$ \\
\hline 1766 & & & 4136 tonnes \\
\hline 1770 & $\begin{array}{l}40000 \text { à } 50000 \text { quintaux } \\
(2205 \text { tonnes) }\end{array}$ & 3748 tonnes & \\
\hline Années 1770 & $\begin{array}{l}6 \text { ou } 8 \text { millions ( } 3400 \\
\text { tonnes) }\end{array}$ & 5780 tonnes & \\
\hline 1785 & 11 millions (5390 tonnes) & 9163 tonnes & \\
\hline Vers 1787 & $\begin{array}{l}9,5 \text { millions ( } 4655 \text { tonnes). } \\
\text { Capacité de } 12,5 \text { millions }\end{array}$ & 7913 tonnes & \\
\hline $\begin{array}{l}\text { Fin Ancien } \\
\text { Régime }\end{array}$ & & $\begin{array}{l}10750 \text { tonnes } \\
\text { (18550000 livres brut, } \\
3385000 \text { terré) }\end{array}$ & \\
\hline 1790 & 13 millions (6370 tonnes) & $\begin{array}{l}10192 \text { tonnes } \\
\text { (7644 brut, } 2548 \text { terré) }\end{array}$ & \\
\hline 1790 & 7000 ou 7840 tonnes & 11900 ou 13328 tonnes & \\
\hline
\end{tabular}

Sources :

- 1697-1698 : Arch. dép. de Loire-Atlantique, C 802. État des sucres moscouades que des raffineurs d'Orléans ont fait entrer en France.

- 1714 : Ibid., C 730. Consommation de diverses raffineries. Une barrique pèse alors 450 livres. Angers : 1400 à 1700 barriques. Saumur : 1400 à 1700 . Orléans : 8200 à 9900 . Nantes : 3100 à 3600 . Orléans représente déjà $60 \%$ du total, et $74 \%$ en amont de Nantes.

- 1711, 1717 à 1726 : Ibid., C 855. RoBIN, Loïc, Le trafic fluvial en Loire au XVIII siècle en amont de Nantes, d'après les sources nantaises, mémoire de maîtrise, Nantes, 1983, p. 57-62.

- 1744 : SAVARY des Bruslons, Dictionnaire universel de commerce [...]. Tome I. Partie II, Genève, héritiers Cramer et frères Philibert, 1744, p. 157.

- 1753, 1761, 1766 : Arch. mun. d'Angers, CC 202 (1753), CC 30 (1761), 31 et 32 (1766). MERLET, Monique, Le péage..., op. cit, p. 154.

- 1770 et 1785 : "Le commerce et l'industrie à Orléans en l'an XIII (1805) ", Bulletin mensuel de la Chambre de Commerce d'Orléans et du département du Loiret, $\mathrm{n}^{\circ}$ 1, 1898.

- Années 1770 : Dion, Roger, "Orléans et l'ancienne navigation de la Loire ", Annales de Géographie, tome $47, \mathrm{n}^{\circ} 266,1938$, p. $128-154$.

- Fin Ancien régime : Arch. nat., F12/1502. S.D. (1795-1796). Évaluation rétrospective.

- 1787 : Ibid., F12/1639A. Mémoire des raffineurs d'Orléans, s.d., vers 1787.

- 1790 : Ibid., F12/562. Mémoire de Tribert (6370 tonnes). - Arch. dép. du Loiret, microfilm 1 Mi 1056 R1. Chambre de commerce d'Orléans, délibération du 15/4/1813 et mémoire du 20/5/1814 (7000 ou 7840 tonnes produites par 30 manufactures). Documents transmis par Gaëlle Caillet. 
$1753^{98}$ et 4136 tonnes en 1766 . De plus, il faut ajouter à la consommation des raffineries d'Orléans, un peu de sucre brut ou terré destiné à celles d'Angers, Saumur et Tours, et peut-être quelques envois de sucre raffiné depuis ces villes vers Orléans et vers Paris ${ }^{99}$. Une tendance émerge de ces données : les quantités de sucre remontant la Loire font plus que doubler en 40 ans, et quadrupler en 70 ans.

Le transport de sucre sur la Loire est très dépendant de la liberté de navigation sur mer. Il passe 17 fois moins de sucre et 6 fois moins de café en 1761, pendant la guerre de Sept Ans, qu'en $1766^{100}$. Par ailleurs, un mémoire attribué au raffineur orléanais Ravot (1772) explique que pendant la guerre de Sept ans, "nous avons été obligés d'avoir recours à Bordeaux qui était presque le seul port où il [le sucre] est arrivé ". Le transport par route a entraîné un énorme surcoût ${ }^{101}$. Un autre mémoire, de 1701 , signale des transports par voie de terre depuis Rouen et La Rochelle vers le bassin de la Loire afin d'éviter la douane d'Ingrandes ${ }^{102}$. Le phénomène paraît cependant limité, et grossi dans le mémoire afin de dénoncer les droits de douane. En sens inverse, Orléans renvoie à Nantes les sirops, résidus des opérations de raffinage, qui sont expédiés en Europe du Nord " pour y être employé à la fabrication du tabac, ou converti en liqueur spiritueuse

98. Arch. mun. d'Angers, CC 202. Journaux du bureau d'Ingrandes, 1753. 2106 tonnes de sucres sont recensées isolément. Les 1937 tonnes restantes correspondent à une évaluation des parts respectives du sucre et d'autres produits (café, riz, bois de teinture...) qui sont évalués en bloc dans les journaux.

99. Ces diverses évaluations ne donnent évidemment qu'un ordre de grandeur à affiner. Les chiffres correspondent au poids net en sucre. Pour obtenir le poids brut des barriques, il faudrait prendre aussi en compte la tare, c'est-à dire la part du poids des barriques dans le poids total brut. La tare est officiellement de 16 ou $17 \%$ en France pour le sucre brut, mais le taux est nettement plus faible en réalité (peutêtre $10 \%$ ), en partie à cause de la forte augmentation de la taille des barriques de sucre au cours du XVIII ${ }^{\mathrm{e}}$ siècle : elles passent d'environ $400 \mathrm{~kg}$ à $1650 \mathrm{~kg}$ net. Un droit de sortie étant perçu sur chaque barrique partant des Îles, les colons tendent à augmenter le poids des barriques de manière à réduire l'impact de cet impôt. Le poids officiel des barriques de sucre est plusieurs fois réévalué pour tenir compte de cette évolution. La part des "futailles " dans le poids brut total diminue à mesure que le volume augmente.

100. 231872 livres de café en 1761, 1490775 livres en 1766. De même, la morue sèche passe à la faveur de la paix de 4 à 16 millions d'unités. MERLET, Monique, Le péage..., op. cit., p. 154 (sucre), 182 (café) et 192 (tabac).

101. En temps de paix, " Nous tirons presque toutes les matières de Nantes par la Loire ". Le transport par route depuis Bordeaux a atteint pendant la guerre le prix de 120 livres t. le " millier " de livre (poids), contre 10 livres t. par la Loire (Archives dép. du Loiret, 11J 239. Mémoire sur l'art et le commerce du raffineur, 1772).

102. Les " peuples de Bretagne [...] sont obligez de tirer les marchandises etrangeres, et autres qui leur sont necessaires, de Rouen, et de La Rochelle, en les faisant voiturer par terre une partie du chemin [...] La Rochelle fournit Tours de Sucre par terre au prejudice de Nantes par eau en evitant le bureau d'Ingrande; \& Rouen fournit toute la Loire jusqu'à Angers même, qui n'est qu'a 18 lieues de Nantes " (Arch. dép. de Loire-Atlantique, C 700. $1 / 6 / 1701$. Griefs du commerce de la Bretagne et de Nantes en particulier, par rapport à la régie des fermes). 
ou pour entrer dans la confection du pain d'épice ${ }^{103}$ " (Chambre de commerce d'Orléans, 1814). Les quantités transportées sur la Loire ne sont pas négligeables. D'après un mémoire de 1761, 225 livres de sucre brut donnent au final, après plusieurs raffinages, 65 livres de sirop ${ }^{104}$, d'où on peut déduire qu'environ 2000 tonnes de sirop descendent la Loire chaque année d'Orléans à Nantes à la fin de l'Ancien régime ${ }^{105}$. S'ajoutent les petites quantités de sirops produits à Saumur et Angers.

\section{Estimation du trafic au milieu du siècle à partir des journaux de la cloison d'Angers}

Il est temps de risquer une estimation globale du trafic, en prenant appui sur les journaux de la cloison d'Angers de 1753 et sur les données recueillies par Monique Merlet pour 1761 et 1766. Le tableau présente un résumé pour les principaux produits (Annexes 5 et 6 ).

En 1753, l'ensemble du trafic mesuré au bureau d'Ingrandes atteint 16220 tonnes. À cela s'ajoutent 10000 tonnes de sel, ainsi que les produits pour lesquels je n'ai pu trouver de correspondance (" cents " de harengs, "fournitures " de cercles de tonneaux, etc.) et qui pèsent probablement quelques centaines de tonnes. Le sel représente donc plus du tiers du trafic remontant. Arrivent ensuite les céréales, avec 4076 tonnes, sachant que cette année 1753 est exceptionnelle. Les autres marchandises importantes sont le sucre (2106 tonnes mesuré isolément), les « drogueries " (502 tonnes), et une catégorie regroupant majoritairement du sucre, combiné à d'autres produits : thé, café, indigo, savon, etc. (2749,6 tonnes); en regroupant parfois " alun et riz ", "sucre et bois d'inde ", ou " sucre et café ", les préposés du bureau d'Ingrandes n'ont pas facilité l'analyse par produit. Émergent aussi la chaux (1 722 tonnes, vers l'aval), le bois sous toutes ses formes (1507 tonnes), le poisson (1 084 tonnes, principalement de la morue), la résine (1 181 tonnes). Le vin vient loin derrière avec 228 tonnes, après la laine (302,6 tonnes). Les journaux du bureau d'Ingrandes n'indiquent pas les destinations des produits, mais on peut au moins déterminer le sens de circulation d'après leur nature. La plupart des marchandises déclarées remontent la Loire en venant de Nantes. Quelques unes proviennent de la zone entre les Pontsde-Cé, Angers et Ingrandes et sont envoyées vers Nantes, cependant elles

103. La conversion des sirops en eau-de-vie est prohibée par la déclaration royale du 24 janvier 1713, afin de préserver le commerce des eaux-de-vie de vins (Arch. dép. du Loiret, 1 Mi 1056 R1. Mémoire du 20/5/1814 adressé au ministre des affaires étrangères). 104. Anonyme, "Mémoire sur le rétablissement des Raffineries de Nantes ", Journal de Commerce, octobre 1761, p. 94-108.

105. Un mémoire rédigé vers 1787 indique pour Orléans une capacité de production de 12,5 millions de livres de sucre (poids) et 5 millions de sirop. En utilisant cette proportion, on arrive aussi à 2000 tonnes de sirop à peu près à la fin de l'Ancien Régime (Arch. nat., F12/1639A. Mémoire des entrepreneurs des manufactures de sucre raffiné d'Orléans adressé à Monsieur). 


\section{Tonnages des marchandises passant aux 3 principaux bureaux du péage de la cloison d'Angers}

\begin{tabular}{|c|c|c|c|c|c|c|c|c|c|}
\hline \multirow[b]{2}{*}{$\begin{array}{l}\text { Bureaux de la } \\
\text { cloison: }\end{array}$} & \multicolumn{3}{|c|}{1753} & \multicolumn{3}{|c|}{1761} & \multicolumn{3}{|c|}{1766} \\
\hline & Ingrandes & $\begin{array}{l}\text { Ponts- } \\
\text { de Cé }\end{array}$ & $\begin{array}{l}\text { Haute } \\
\text { chaine }\end{array}$ & Ingrandes & $\begin{array}{l}\text { Ponts } \\
\text { de Cé }\end{array}$ & $\begin{array}{l}\text { Haute } \\
\text { chaine }\end{array}$ & Ingrandes & $\begin{array}{l}\text { Ponts } \\
\text { de Cé }\end{array}$ & $\begin{array}{l}\text { Haute } \\
\text { chaine }\end{array}$ \\
\hline Céréales & 4076,5 & 1212,9 & 82,1 & 165,8 & 18247,1 & 104 & 255,9 & 25720,33 & 220,7 \\
\hline Fèves & & 1155 & & & 673,3 & & & 3072,3 & \\
\hline $\begin{array}{l}\text { Sel (évalua- } \\
\text { tion) }\end{array}$ & 10000 & & & 11000 & & & 11500 & & \\
\hline $\begin{array}{l}\text { Tuffeaux (a) } \\
/ / \text { carreaux, } \\
\text { pierres des } \\
\text { Rairies (b) }\end{array}$ & & $\begin{array}{c}11625 \\
\text { (a) }\end{array}$ & $\begin{array}{l}3056 \\
\text { (b) }\end{array}$ & & $\begin{array}{l}10100 \\
\text { (a) }\end{array}$ & $\begin{array}{c}683,9 \\
\text { (b) }\end{array}$ & & $\begin{array}{l}10400 \\
\text { (a) }\end{array}$ & $\begin{array}{c}2322 \\
\text { (b) }\end{array}$ \\
\hline Ardoise & & 2251 & & & 2054,1 & & & 2580,6 & \\
\hline $\begin{array}{l}\text { tous bois, } \\
\text { merrain, } \\
\text { osiers, tan }\end{array}$ & 1509,1 & 30061 & 19941 & 630,4 & 9612,8 & 12808,4 & 850,5 & 9305,4 & 14168,6 \\
\hline $\begin{array}{l}\text { textiles / } \\
\text { mercerie }\end{array}$ & 17,5 & 1320 & & 46,2 & 828,5 & & 16,6 & 1034,7 & \\
\hline fer et acier & 3,2 & 1701,2 & 434,7 & 0,8 & 1004,7 & 470 & 0,8 & 2235,3 & 310,9 \\
\hline Chaux & 1721,9 & 0 & & 1671,5 & 0 & & 3181 & & \\
\hline $\begin{array}{l}\text { Sucre, drogue- } \\
\text { ries, épiceries }\end{array}$ & 5444,46 & & & 1486,2 & & & 7995,67 & 21,8 & \\
\hline $\begin{array}{l}\text { autre et non } \\
\text { évalué }\end{array}$ & 3718,14 & 3440,7 & 1555,3 & 4664,2 & 3787,7 & 1308,3 & 4897,53 & 7547,37 & 1307,1 \\
\hline $\begin{array}{l}\text { Vin (dont } \\
\text { hypothèse par } \\
\text { voie de terre) }\end{array}$ & 229,2 & $\begin{array}{l}9893 \\
(2500 \\
\text { terre })\end{array}$ & & 381,8 & $\begin{array}{l}5428 \\
(2000 \\
\text { terre })\end{array}$ & 53,6 & 381,8 & $\begin{array}{c}8375,2 \\
(2500 \\
\text { terre) }\end{array}$ & 11,7 \\
\hline TOTAL & 26720 & 62659,8 & 24987 & 20046,9 & 51736,2 & 15656,4 & 29079,8 & 70293 & 18717,3 \\
\hline
\end{tabular}

Sources : Arch. mun. d'Angers, CC 202 (1753), CC 30 (1761), 31 et 32 (1766); MERLET, Monique, Le péage..., op. cit., pour le dépouillement des journaux de 1761 et 1766 . Simple évaluation pour le sel.

représentent un faible volume au regard de l'ensemble du trafic : il s'agit principalement de chaux, de bois et de vin.

Passons maintenant au bureau des Ponts-de-Cé. Ici, la plupart des marchandises taxées descendent la Loire, sauf celles qui franchissent le pont (bétail ${ }^{106}$ et vin), ou qui sont chargées dans la zone entre les Pontsde-Cé, Angers et Ingrandes (principalement des ardoises envoyées vers Tours, Orléans et Paris). Le volume global est beaucoup plus important qu'à Ingrandes et représente 62 159,8 tonnes. Le bois émerge fortement, avec 24058 tonnes (38,7 \%), auxquelles s'ajoutent 2872 tonnes de merrain pour les barriques. Viennent ensuite le tuffeau (11625 tonnes) et le vin (9893 tonnes en poids net, sans les barriques). Une grande part du vin, pro-

106. Je n'ai pas intégré dans les divers tableaux le bétail franchissant les ponts. Les bovins sont envoyés en Normandie, dans le Maine et au nord d'Angers dans des paroisses en bord de rivières disposant de prairies naturelles. Pour information, en 1753, il passe sur les ponts de Cé, pour le commerce, 12861 moutons, 4448 vaches, 2117 boeufs, 34 chevaux (destinés à la vente), et 23 mules. On voit aussi passer aux Ponts-de-Cé des charges de " mitraille ", ou vieux cuivre, destiné à Villedieu-les-Poêles en Normandie. 
bablement autour de 2500 tonnes, passe sur les ponts de Cé pour gagner Angers et le Maine. Le vin angevin, en « busses ", représente 60,7 \% du total, et celui d'amont, en " poinçons ", 39,3\%. Loin derrière, on trouve l'ardoise (2251,5 tonnes, dont une grande partie dirigée vers l'amont), les tissus et merceries (1320 tonnes), le froment (1 147 tonnes), les fèves (1 155 tonnes).

Le bureau de la Haute Chaîne, à la limite nord d'Angers sur la Maine, voit aussi passer des quantités impressionnantes de bois : 19940,8 tonnes de bois à brûler, de bois d'ouvrage, et secondairement de merrain. Ce bois représente $81 \%$ du total, principalement à destination de Nantes (Annexe 6) ${ }^{107}$. Á cela s'ajoutent des carreaux, briques et pierres venant certainement du village des Rairies, près du Loir (3056 tonnes, à destination de Nantes), du fer (434,7 tonnes) et de la farine (310,9 tonnes). Le trafic sur la Maine est massivement descendant. Les marchandises venant de l'aval, telles le vin, ne sont pas déclarées ici car elles l'ont déjà été aux autres bureaux (ceux des Ponts-de-Cé et de La Pointe en particulier); elles représentent certainement des masses bien inférieures à celles du bois. Au total, 9474,5 tonnes sont déclarées pour Nantes à la Haute Chaîne, mais en tenant compte des absences de déclarations, il est probable que parmi les marchandises descendantes, 15000 à 20000 tonnes (sur 24687) traversent Angers pour être dirigées vers Nantes.

Enfin, à Bouchemaine, on ne dispose d'informations que de janvier à septembre inclus (Annexe 6). Le trafic est seulement de 4069,1 tonnes : du bois destiné à Angers (2453,9 tonnes), et du vin envoyé dans le Maine, principalement.

Le trafic sur la Loire, tel qu'il se dessine en 1753, est pour les trois quarts descendant. Une partie des bateaux sont " déchirés " à Nantes. D'autres remontent la Loire, mais souvent à vide ou avec des charges limitées. Le déséquilibre du trafic a un effet sur la résidence des voituriers. En Anjou, en Touraine et en Orléanais, les marchands font appel de préférence à des voituriers qu'ils connaissent, et qui habitent à proximité : dans les procèsverbaux, l'origine géographique des voituriers recoupe généralement celle des marchandises ${ }^{108}$. La situation est différente à Nantes, car les voituriers

107. Un tiers est déclaré pour Nantes, mais la part de cette ville est probablement bien plus grande en réalité, car dans les trois quarts des cas les destinations des marchandises ne sont pas indiquées.

108. La résidence des voituriers est connue dans 261 procès-verbaux sur 263. Deux grandes villes dominent : Orléans (46 voituriers) et Tours (39). Viennent ensuite Saumur (18), Angers (16), Châtellerault (15), Saint-Clément-des-Levées (14), Nantes (9), Les Pontsde-Cé, Blois et Chinon (8 chacun). 101 sur 261 sont Angevins. La résidence des simples mariniers constituant les équipages à la remontée est aussi plus aléatoire qu'à la descente. Les mariniers sont en général gagés par voyage, et ils peuvent changer d'employeur à leur arrivée, ce qui arrive particulièrement à Nantes où les voituriers peuvent attendre longtemps avant de trouver de nouvelles marchandises. Des relations personnelles de confiance interviennent sûrement dans de nombreux cas, mais le mouvement sur la Loire entraîne aussi des relations plus ponctuelles et circonstancielles entre voituriers et mariniers. Ibid., ? 1 ET E 12. Chambre de commerce de Nantes. Lettre du 30 juillet 1807. " Il est notoire dans notre ville que les compagnons de bateaux sont à gage pour le voyage; qu'ils 
nantais jouent un rôle très secondaire dans les transports vers l'amont (89 Nantais sur 1431 passages à Ingrandes en 1753 , soit $6,2 \%{ }^{109}$. Ils sont concurrencés rudement par les nombreux voituriers de Saumur, Tours ou Orléans, qui une fois arrivés à Nantes, cherchent des chargements pour ne pas remonter à vide. Les Nantais ont aussi moins de chances, une fois arrivés à l'issue d'un voyage vers l'amont, de trouver des marchandises pour redescendre.

Les marchandises traditionnelles dominent : sel, bois, pierres, vin, poisson. En provenance de l'aval viennent en outre de nouvelles productions, dominées par le sucre, associé à d'autres produits coloniaux (indigo, café) ou méridionaux (savon, huile d'olive). Dans ces journaux, comme dans les procès-verbaux, Nantes est le cœur du trafic. L'essentiel de ce qui passe au bureau d'Ingrandes en vient. Aux Ponts-de-Cé, Nantes représente 70 \% des destinations en masse (43536 tonnes), et la catégorie imprécise "Angers et Nantes " $3 \%$ (1851,6 tonnes) ${ }^{110}$. Au total, l'ensemble du trafic avec Nantes représente donc, en additionnant la remontée et la descente, et en tenant compte de la Haute Chaine, environ 86000 à 90000 tonnes.

Quelles évolutions apparaissent en 1761 et 1766, à travers les données relevées par Monique Merlet? En 1761, le trafic à Ingrandes diminue fortement, en raison à la fois d'un effondrement du sucre et autres " épiceries ", n'arrivant plus à Nantes à cause de la guerre, et d'un retour à la normale pour le commerce des céréales, par rapport à 1753 (114 tonnes au lieu de 4076 tonnes) ${ }^{111}$. Aux Ponts-de-Cé, la quantité de bois baisse fortement, mais dans le même temps la part des céréales augmente (17670 tonnes au lieu de 1 146). À la Haute Chaine, le bois diminue aussi, d'un tiers (19941 à 12940 tonnes).

En 1766, la masse des marchandises passant à Ingrandes, en intégrant le sel, dépasse celle de 1753 et atteint 29080 tonnes. La hausse est en grande partie due à celle de la chaux dirigée vers l'aval (3181 tonnes au lieu de 1700 environ), ainsi qu'aux "drogueries " et au sucre. Le trafic aux Pontsde-Cé augmente également, et atteint 70293 tonnes, dont 24745,5 tonnes de froment (35,2\%). Le bois et le vin conservent une part importante.

La Loire a une grande importance pour le commerce et l'économie des régions traversées; elle favorise les échanges et le développement de pro-

se gagent ailleurs ou retournent dans leur pays aussitôt qu'il est fini; que les maitres n'en gagent d'autres qu'au moment du départ."

109. Cela s'observe aussi dans les procès-verbaux : seuls 9 voituriers sur 95 remontant de Nantes sont nantais. Au total, 10 voituriers nantais apparaissent sur 263 procès-verbaux. Le dixième revient d'Orléans.

110. Des marchandises sont parfois déclarées pour " Angers et Nantes ", sans distinction. 111. J'ai dû remplacer les chiffres avancés pour le poisson par Monique Merlet, par une évaluation de 1100 tonnes tirée des journaux de 1753. Monique Merlet fournit pour les morues des données en livres, qui paraissent incohérentes. Elle s'est apparemment embrouillée dans son mode de calcul, tout en ne donnant pas le détail des données de base. Il faudrait refaire l'analyse à partir des journaux de la cloison. 
Figure 5 - Marchandises déclarées aux 3 principaux bureaux de la cloison d'Angers. 1753, 1761, 1766.
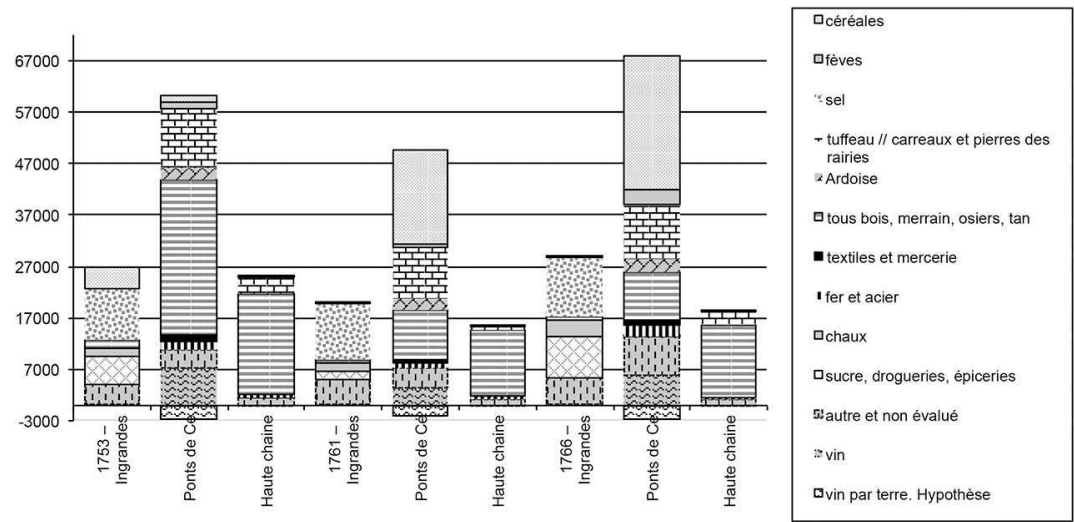

Sources : Arch. mun. d'Angers, CC 202 (1753), CC 30 (1761), 31 et 32 (1766); MERLET, Monique, Le péage..., op. cit., pour le dépouillement des journaux de 1761 et 1766 .

ductions commerciales. Les villes de Nantes, Angers, Saumur et Orléans jouent le rôle de relais et d'entrepôts, essentiels en raison des ruptures de charges, de la lenteur du transport fluvial et de son irrégularité. Plusieurs marchandises dominent le trafic : le bois, le tuffeau, le blé, le sel, le vin, et de plus en plus, le sucre ${ }^{112}$. L'importance du transport du bois sur cette section de la Loire est une des surprises apparues lors de l'étude. Les mémoires de l'administration ou de la chambre de commerce de Nantes n'abordent qu'exceptionnellement le bois, le tuffeau et la cherrée ${ }^{113}$. On est bien mieux renseignés sur le blé, le vin, le sel ou le sucre, marchandises plus coûteuses, soumises à des taxes importantes, ou d'une importance stratégique pour l'alimentation. L'étude des journaux de la cloison permet de porter un regard différent sur l'importance respective de ces marchandises dans le trafic fluvial.

Des évolutions apparaissent sur le court terme comme sur le long terme. Elles sont difficiles à saisir en raison de l'éparpillement et du caractère lacunaire des sources. On observe de fortes fluctuations quant à l'importance relative du bois, du blé, et des produits coloniaux. Elles sont dues aux guerres, aux variations de l'offre et de la demande, enfin à des décisions politiques. À l'opposé, le commerce du sel et du tuffeau paraît beaucoup

112. Dans une étape ultérieure, il sera intéressant d'étudier ces marchandises du point de vue de leur valeur, sachant qu'un tonneau de vin ou de blé vaut bien plus que le même poids en tuffeau ou en bois.

113. Résidus de cendres de lessives utilisés comme engrais dans les régions d'Ancenis et Ingrandes. 
plus régulier. Sur le long terme, l'essor des marchandises coloniales, en particulier du sucre, apparaît clairement.

Nantes occupe une place centrale dans ces échanges. Ce port entretient des relations privilégiées avec Orléans à la "remontée ", et avec l'Anjou à la "descente ", mais plus largement, son influence s'étend loin en amont dans le bassin de la Loire. Il fournit le sel, les marchandises coloniales et celles du Midi, tout en drainant vers la Bretagne et vers la mer, les produits agricoles, les matières premières et les produits manufacturés. Inversement, si on déplace le regard, le trafic fluvial est très important pour le port de Nantes. Son rôle d'interface entre l'océan et un immense arrière-pays est son principal atout et fait toute la différence avec les ports de Saint-Malo ou de Lorient. Le rapprochement est éclairant, entre les 63000 à 90000 tonnes que représentent les échanges de Nantes avec la Loire " amont ", dans les années 1753, 1761 et 1766 , et les 100000 à 150000 tonneaux auxquels Paul Jeulin estime le trafic maritime de Nantes au milieu du XVIII ${ }^{\mathrm{e}}$ siècle $^{114}$. Au siècle suivant, Nantes doit faire face à l'évolution de son rôle d'interface, provoquée par la décadence de la marine de Loire et par l'essor du chemin de fer.

114. On ne peut cependant comparer directement une tonne, unité de masse, et un tonneau, pouvant correspondre aussi bien à une masse qu'à un volume. L'intérêt est dans l'ordre de grandeur. En 1753, les échanges entre Nantes et l'amont, à la descente et à la remontée, représentent autour de 85000 à 90000 tonnes en additionnant les données des principaux bureaux de la cloison et une estimation pour le sel. On passe probablement autour de 63000 et 86000 tonnes en 1761 et 1766 . Paul Jeulin évalue le trafic du port maritime entre 100000 et 150000 tonneaux pour la période 1748-1753, et il cite le chiffre de 158546 tonneaux donné par Expilly en 1764 (JeuLin, Paul, L'évolution du port de Nantes, organisation et trafic depuis les origines, Paris, Presses universitaires de France, 1929, p. 229). 
Quel commerce fluvial en Loire angevine au XVIII ${ }^{\mathrm{e}}$ siècle?

\section{Annexe 1 - Marchandises à destination de Nantes dans les procès-verbaux d'avarie et de retards}

\begin{tabular}{|c|c|c|}
\hline Chargements & Villes & Marchandises \\
\hline & Anjou (36) & $41,8 \%$ \\
\hline 1 & Champtoceaux & Vin \\
\hline 2 & Chalonnes & Charbon \\
\hline 4 & Angers, Ponts-de-Cé & $\begin{array}{c}\text { Ardoise } 3 \text {, divers } 1 \text { (lin, bouteilles, } \\
\text { bougies, cordes) }\end{array}$ \\
\hline 1 & La Bohalle & Fèves \\
\hline 1 & Beaufort (Ménitré) & Seigle \\
\hline 1 & Juigné-sur-Loire & Vin \\
\hline \multirow[t]{2}{*}{26} & $\begin{array}{c}\text { Saumur (12) et Saumurois, des } \\
\text { Rosiers (4) à Chouzé }\end{array}$ & $\begin{array}{l}\mathbf{3 0 , 2} \%) \text { Froment et seigle (17 vin (2) } \\
\text { fèves (3) avoine (1) tuffeau (1) char- } \\
\text { bon (1), épiceries (1) }\end{array}$ \\
\hline & Touraine - Orléanais (27) & $31,4 \%$ \\
\hline 1 & Chapelle-sur-Loire & Froment et seigle \\
\hline 7 & Tours & $\begin{array}{l}\text { Bois (1 en bateau) terre jaune (1) } \\
\text { draps (2) divers } 2 \text { (cuir, toiles, étoffes, } \\
\text { pois, confitures, pruneaux) inconnu } \\
\text { (1) }\end{array}$ \\
\hline 3 & Blois & Blé (1), farine (1), vin (1) \\
\hline 1 & Amboise & Farine \\
\hline \multirow[t]{2}{*}{15} & Orléans $(16,8 \%)$ & $\begin{array}{l}\text { Varié et composite : sirop, poudre à } \\
\text { canons, chanvre, lin, vin (2), farine ( } 3 \text { ), } \\
\text { verres (1), fromages, armes, draperies, } \\
\text { bonnets, papier... }\end{array}$ \\
\hline & Sur le Cher (4) & $4,7 \%$ \\
\hline 3 & Vierzon (sur le Cher) & Bois (échargeaux ou radeaux) \\
\hline \multirow[t]{2}{*}{1} & Saint-Aignan (sur le Cher) & Fer et vins \\
\hline & Sur la Vienne (9) & $10,5 \%$ \\
\hline 2 & Chinon & Bois en bateaux, froment \\
\hline 6 & Châtellerault & $\begin{array}{l}\text { Blé, avec un peu de coutellerie pour } \\
\text { compléter }\end{array}$ \\
\hline \multirow[t]{2}{*}{1} & Port-de-piles & Blé \\
\hline & Haute Loire et Allier (8) & $9,3 \%$ \\
\hline 1 & Cosne & Fer \\
\hline 2 & Diou & Bois (1 en bateau, 1 en échargeaux) \\
\hline 1 & Roanne & Charbon \\
\hline 1 & Saint-Satur (près Cosne) & Terre jaune \\
\hline 1 & Moulin & Bois (échargeaux ou train de bois) \\
\hline \multirow[t]{2}{*}{2} & Nevers & Fayence \\
\hline & Autre & $2,3 \%$ \\
\hline 1 & Avenières, près Laval & Bois (échargeaux) \\
\hline 1 & Sougé-sur-Braye (affluent de la Sarthe) & Bois (échargeaux) \\
\hline
\end{tabular}

99 chargements destinés à Nantes, sur 124 descendants à la destination connue. Sur ces 99,86 sont d'origine connue.

Sources : Arch. dép. de Maine-et-Loire, sous-série 5E. Actes notariés. Procès-verbaux d'avaries, naufrages et retards de livraison. 


\section{Annexe 2-Marchandises au départ de Nantes dans les procès-verbaux d'avaries et de retards}

\begin{tabular}{|c|c|}
\hline 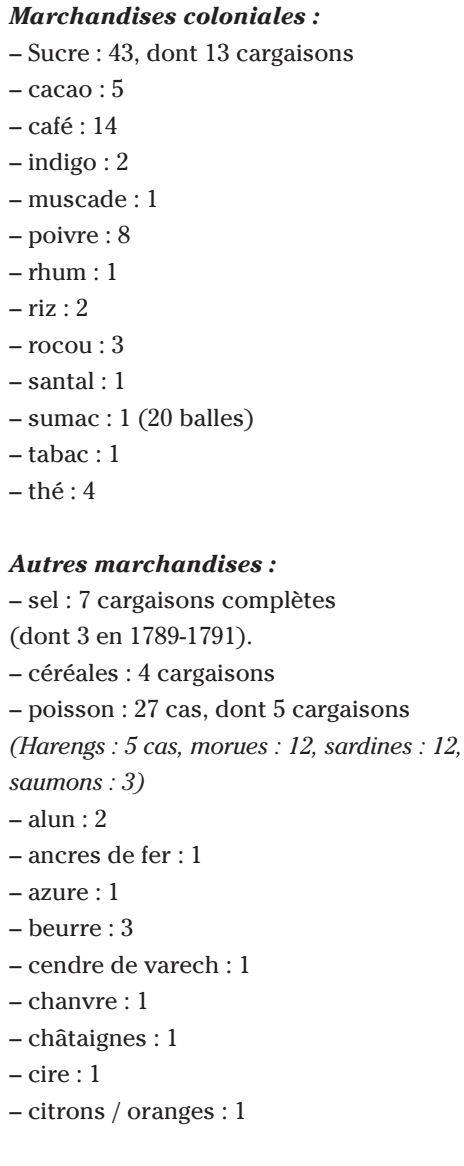 & $\begin{array}{l}\text { - confiture : } 2 \\
\text { - brais gras : } 1 \text { (Goudrons obtenus par la distil- } \\
\text { lation des bois non résineux) } \\
\text { - couperose : } 4 \\
\text { - cuir : } 1 \\
\text { - eau de vie : } 2 \\
\text { - fer : } 2 \\
\text { - fromage : } 3 \\
\text { - fruits (raisins) : } 1 \\
\text { - fruits (figues) : } 1 \\
\text { - garance : } 1 \\
\text { - gourme : } 1 \\
\text { - huiles : } 13 \\
\text { - huitres : } 2 \text { cargaisons } \\
\text { - laine : } 4 \\
\text { - liège : } 1 \\
\text { - liqueurs : } 3 \\
\text { - meubles } ; 1 \\
\text { - moutarde : } 1 \\
\text { - noix de galle : } 2 \\
\text { - passagers : } 2 \\
\text { - peaux : } 5 \\
\text { - pierres à aiguiser }: 1 \\
\text { - pierres de moulage }: 1 \\
\text { - plomb : } 2 \\
\text { - résine : } 4 \\
\text { - savon : } 12 \\
\text { - souffre : } 1 \\
\text { - tissus : } 3 \text { (mouchoirs, laine, toile de Jouy) } \\
\text { - sacs vides : } 1 \\
\text { - terre de poussanne }: 2 \text { dont } 1 \text { cargaison } \\
\text { - vin : } 7 \text {, dont } 1 \text { cargaison. } \\
\end{array}$ \\
\hline
\end{tabular}

Occurrence des marchandises, parmi 92 chargements connus et non vides.

Les cargaisons uniformes, correspondant à des volumes importants, sont précisées.

Sources : Arch. dép. de Maine-et-Loire, sous-série 5E. Actes notariés. Procès-verbaux d'avaries, naufrages et retards de livraison. 


\section{Annexe 3 - Procès-verbal d'avarie pour des marchandises destinées à transiter par Orléans}

Source : Arch. dép. de Maine-et-Loire, 5E16/269.

Les marchandises sont souvent variées dans les bateaux chargés "d'épiceries " en provenance de Nantes, et dans ce procès-verbal, la diversité des produits est marquée. Le rôle d'intermédiaire d'Orléans, ici avec Lyon, Dijon et Paris apparaît clairement. Les 10 barriques de café représentent un chargement inhabituel par son importance. Un autre procès-verbal, du 30/8/1786, passé devant Langlois, notaire de Varennes-sousMontsoreau, est beaucoup plus représentatif : il recense 20 barriques de sucre pour une de café (Arch. dép. de Maine-et-Loire, 5E45/23). Les mots entre crochets et les caractères gras ont été ajoutés au texte afin d'en améliorer la lisibilité.

Le quinzième jour de may sur les cinq heures du soir, mil sept cent soixante seize.

Nous Anne Julie Pierre Rogeron licentié es loix et notaire royal à Beaufort pour la residence de la marsaulaye sur la paroisse de Saint-Mathurin sommes transporté à la réquisition de Pierre Arnois voiturier par eau demeurant paroisse de Saint nicolas de la ville de nantes avec Charles Chartier, René Chartier charpentiers demeurants ditte paroisse de Saint Mathurin, et Vincent Bribard journallier demeurant au canton de la Sablonnière paroisse de la Bohalle nos témoins pour voir et visiter l'avarie et accident arrrivé sur les deux heures après midy de ce jour sur le sixieme et dernier batteau du train dudit Pierre Arnois au millieu de la riviere de loire vis à vis du lieu de la grande Sablonniere ditte paroisse de la Bohalle occasionné par un sicot et restant d'un bâton de quartier planté dans le sable et etant arrivé dans lesdits battaux conjointement avec luy il nous a fait voir qu'effectivement ledit batteau etoit au fond et nos témoins accompagnés dudit arnois ont arraché le restant dudit bâton qui a fait la fracture dans l'Epaule gauche dudit batteau de la longueur de trois pieds sur environ dix poulces de large : ce qui en a occasionné le submergement au même instant sans avoir pû y remédier : et n'ayant pû alors par nous même et nos témoins voir la cariaison [cargaison] d'icelluy batteau nous nous serions transportés conjointement avec le dit arnois dans le voisinnage pour avoir du secours pour mettre hors d'eau et tirer du danger evidant les marchandises dont il est chargé et ayant trouvé ledit secours au nombre de trente personnes à force d'ouvrages [en marge : "pendant tout le cours de la nuit "] auroient tirés d'eau ledit batteau et conduit au port du dit lieu de la Sablonnière afin de decharger les marchandises dont il est chargé pour les faire reconnoitre et pour le compte des marchands à qui elles appartiennent

\section{[marchandises :]}

a été trouvé premierement dix barriques de caffé en grain lesquelles barriques ont crevé au moyen que la marchandise a enflé dans la tonne sur les deux heures après minnuit, les quelques barriques sont marquées sous les lettres $\mathrm{AB}$ pour le compte du sieur huguet negotiant à orléans en passe de bout pour lion, chargés par les sieurs feydeau et Thibault de nantes, sui- 
vant leur lettres de voiture à nous par luy représentées et au même instants remises, en datte du trois de ce mois.

en second lieu le dit arnois nous a declaré qu'il y avai douze milliers de bois rouge pesant, pour le compte du sieur Pottier de la Gueulle negotiant à orleans, chargé par Monsieur Villemain négotiant à nantes le vingt sept avril dernier,

$3^{\circ}$ quatre bariques de sucre blanc pour le compte des dames veuve Chassaing et paupaille en passe de bout au compte de monsieur Bazire de Dijon envoyées par le sieur Schweighauses negotiant à nantes en datte du trente avril dernier marquées sous les lettres BS.

$4^{\circ}$ quatre barriques de sucre brut faisant partie de vingt neuf pour le compte de mesdames $\mathrm{V}$. Chassaing et paupaille en passe de bout pour le compte du dit sieur Bazire de Dijon chargées par le même de l'article trois cy dessus le même jour et an, et marquées sous les mêmes lettres BS.

$5^{\circ}$ Douze balles de lainne en poil au compte des srs Pinchinat et fils et Louvel negotiants à orleans par pierre morin et vallin negotiants à nantes en datte du trois de ce mois, marquées des lettres AL.

$6^{\circ}$ six balles de poivre en grain, au compte du sieur Lefevre negotiant à orléans en passe de boût pour paris chargées par le sieur ferron l'aisné negociant à nantes les trois may dernier marquées sous la lettre $\mathrm{F}$ enclose d'une etoile en bas de la quelle est un treffle

$7^{\circ}$ Un tiercon de vin rouge de Bordeaux chargé pour le compte du sieur haime de St. Mars près Tours [Cinq-Mars-la-Pile] par le sieur andrieux negotiant à nantes le douze avril ernier marqué sous les lettres MC.

$8^{\circ}$ enfin un autre tiercon de vin rouge de St Emilion chargé pour le compte du sieur Delimay ${ }^{115}$ ingenieur à Tours, par ledit sr. andrieux, et le même jour sous la lettre $\mathrm{L}$.

Desquelles marchandises ledit arnois nous auroit mis en main les lettres de voiture et a luy remises, au même instant, et nous a déclaré qu'il alloit faire decharger au même endroit les dittes marchandises pour les faire mettre en lieux surs pour les faire soigner crainte du déperissement aux risques, perils et fortunes de qui il appartiendra, declarant qu'il n'y a aucunnement de son deffaut ny des gens qui composent son equippe aux protestations faittes par luy que le dit avarie ou submergement ne pourra luy nuire ny préjudicier sauf à luy se pourvoir ainsy quil avisera bon être, et a déclaré qu'il alloit mettre du monde pour soigner les marchandises qui doivent l'être, aussy aux risques de qui il appartiendra de tout quoy et de tout ce que dessus il nous a requis acte que nous luy avons decerné et octroyé et l'avons jugé de son consentement et à sa réquisition : fait et redigé le présent procès-verbal tant de la datte du quinze may et que ce jour seize dudit mois tant dans les batteaux cy dessus que dans le port dudit lieu de la Sablonniere ditte paroisse de la Bohalle presence des témoins cy dessus denommés que de paul et jean les

115. De Limay est l'ingénieur qui a la charge de la construction, alors en cours, du " pont de pierre à Tours". 
Chudeaux pescheurs et charpentiers en batteaux qui ont vû et visité laditte fracture et attesté être veritable, lesdits Chudeaux demeurants ditte paroisse de Saint Mathurin / deux mots rayés nuls en marge, pendant tour le cours de la nuit approuvé.

[Signatures :] pierre arrois Chartiertier

Ledit bribard a declaré ne scavoir signer de ce enquis

Pierre arrois chartier jeanchudeau

charles chartier paul chudeau

Rogeron no.[tai]re

Con[trô]llé à Beaufort le 16 may 1776

Quatorze sols Aubry.

Bilan en masse ${ }^{116}$ : Café, 10 barriques $=5390 \mathrm{~kg}$ brut

Bois rouge, 12 milliers $=5880 \mathrm{~kg}$. Sucre, 8 barriques $=6468 \mathrm{~kg}$ brut.

Laine en poil, 12 balles $=882 \mathrm{~kg}$ environ. Poivre, 6 balles $=441 \mathrm{~kg}$ environ.

Vin, 2 tierçons = 304 litres net (et probablement $40 \mathrm{~kg}$ de futaille).

116. D'après le livre des magasins des frères Chaurand à Nantes, vers 1784 , une barrique de café pèse environ $1100 \mathrm{~kg}$ brut, une barrique de sucre brut $1650 \mathrm{~kg}$ (Archives dép. de Loire-Atlantique, $101 \mathrm{~J} 48$ ). Le tierçon fait $1 / 3$ de pipe, ou $2 / 3$ de busse ou de poinçon, soit 152 litres. Une balle de marchandises pèse souvent 150 livres. 


\section{Annexe 4 - Journal de la cloison d'Angers Bureau des Ponts-de-Cé (avril 1753)}

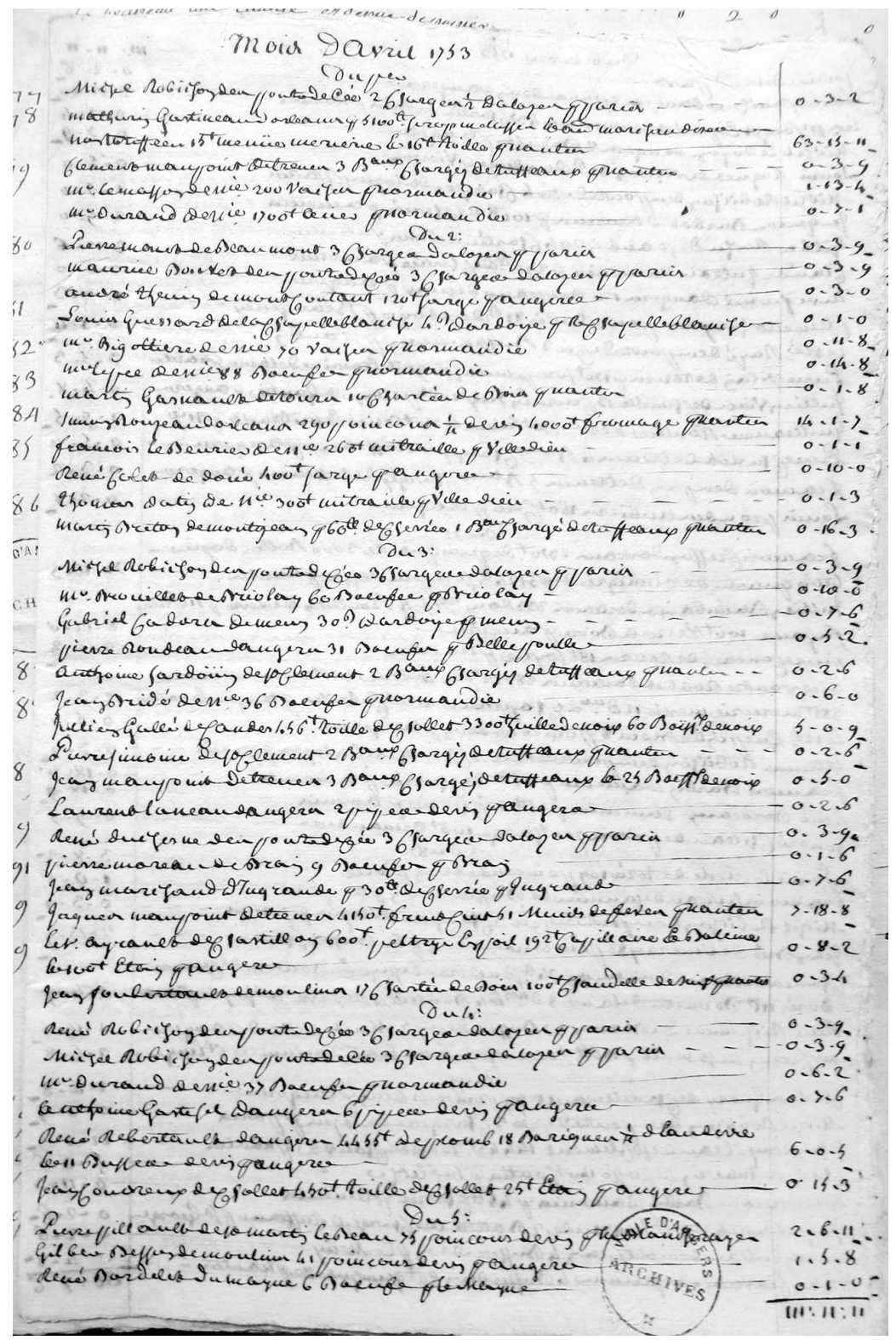

Source : Arch. mun. d'Angers, CC 202. Les noms et résidences des déclarants sont indiqués, ainsi que les destinations. Certains produits passent sur les ponts, et non en dessous : notamment la mitraille pour Villedieu-les-Poêles (Normandie), les bovins pour le Maine et la Normandie, et une partie du vin. 
Quel commerce fluvial en Loire angevine au XVIII ${ }^{\mathrm{e}}$ siècle?

\section{Annexe 5 - Marchandises déclarées aux bureaux de la cloison, à Ingrandes et aux Ponts-de-Cé (1753, 1761 et 1766)}

\begin{tabular}{|c|c|c|c|c|c|c|}
\hline & \multicolumn{2}{|c|}{1753} & \multicolumn{2}{|c|}{1761} & \multicolumn{2}{|c|}{1766} \\
\hline & $\begin{array}{l}\text { Ingrandes } \\
\text { Remontée => }\end{array}$ & $\begin{array}{l}\text { Ponts de Cé } \\
\text { Descente <= }\end{array}$ & $\begin{array}{l}\text { Ingrandes } \\
\text { Remontée => }\end{array}$ & $\begin{array}{l}\text { Ponts de Cé } \\
\text { Descente <= }\end{array}$ & $\begin{array}{c}\text { Ingrandes } \\
\text { Remontée => }\end{array}$ & $\begin{array}{l}\text { Ponts de Cé } \\
\text { Descente <= }\end{array}$ \\
\hline Céréales & $\begin{array}{c}4076,5 \\
(95 \% \text { seigle) }\end{array}$ & $\begin{array}{c}1147 \text { froment } \\
11,8 \mathrm{t} \text {. orge } \\
54,1 \text { avoine }\end{array}$ & $\begin{array}{l}114,1 \text { froment } \\
51,7 \text { avoine }\end{array}$ & $\begin{array}{c}17670 \text { froment } \\
54,2 \text { orge } \\
66,7 \text { seigle } \\
456,2 \text { avoine }\end{array}$ & 255,9 t. froment & $\begin{array}{c}\mathbf{2 4 7 4 5 , 5} \\
\text { froment } \\
29,4 \text { orge } \\
15,8 \text { seigle } \\
929,6 \text { avoine }\end{array}$ \\
\hline Fèves & & 1155 & & 673,3 & & 3072,3 \\
\hline Farine & & $\begin{array}{c}48,5 \\
\text { (385 quarts) }\end{array}$ & & 246,5 & 39,1 & 859,1 \\
\hline Fruits cuits & & 90 & & 128,1 & & 287,7 \\
\hline Fruits crus & & 32,5 & & 11,8 & & 3,4 \\
\hline $\begin{array}{l}\text { Aliments divers } \\
\text { (confiture, noix, } \\
\text { fromage...) }\end{array}$ & $\begin{array}{c}1,2 \text { noix } \\
1,65 \text { confit. } \\
11,2 \text { orang. } \\
(3366 \text { £) } \\
2,7 \text { divers } \\
2 \text { riz } \\
8,4 \text { beurre }\end{array}$ & $\begin{array}{c}44 \text { noix } \\
\text { (7333 bois- } \\
\text { seaux) } \\
154,8 \text { pois } \\
23,6 \text { from. } \\
2,2 \text { divers }\end{array}$ & $\begin{array}{c}2,1 \text { fromage } \\
11,2 \text { oranges } \\
3,4 \text { riz } \\
29,5 \text { divers } \\
15,9 \text { beurre }\end{array}$ & $\begin{array}{c}27,4 \text { t. noix } \\
254,8 \text { t. pois } \\
90,4 \text { t. fromage } \\
12,91 \text { t. divers }\end{array}$ & $\begin{array}{c}0,7 \text { fromage } \\
13,7 \text { riz } \\
1,2 \text { oignon } \\
86,5 \text { divers } \\
8,3 \text { beurre }\end{array}$ & $\begin{array}{c}50,8 \text { noix } \\
882 \text { pois } \\
60,7 \text { fromage } \\
86,3 \text { divers }\end{array}$ \\
\hline $\begin{array}{l}\text { Graines lin, } \\
\text { moutarde, } \\
\text { "graines de } \\
\text { jardin" }\end{array}$ & $\begin{array}{c}12,4 \text { lin } \\
9,5 \text { moutarde }\end{array}$ & & $\begin{array}{l}7,6 \text { graine } \\
\text { de lin }\end{array}$ & $\begin{array}{l}1 \text { graines de } \\
\text { jardin }\end{array}$ & $\begin{array}{c}5,29 \text { moutarde } \\
9,3 \text { graine lin }\end{array}$ & $\begin{array}{l}\text { 42,4 graines de } \\
\text { jardin }\end{array}$ \\
\hline $\begin{array}{l}\text { Huile végétale et } \\
\text { non précisé }\end{array}$ & 20,4 & 129,6 & 17,6 & 63,8 & 3,7 & 42,4 \\
\hline $\begin{array}{l}\text { Huile de } \\
\text { poisson }\end{array}$ & 128,4 & 1,9 & 66,7 & 6 & 145,3 & \\
\hline $\begin{array}{l}\text { Vin } \\
\text { poids net }\end{array}$ & 229,2 & $\begin{array}{c}9893 \\
\text { (dont } 2500 \\
\text { par terre?) }\end{array}$ & 381,8 & $\begin{array}{c}5428 \\
\text { (dont } 2500 \\
\text { par terre?) }\end{array}$ & 85,3 & $\begin{array}{c}8375,2 \\
\text { (dont } 2000 \\
\text { par terre?) }\end{array}$ \\
\hline Eau de vie & 7,1 & 102 & & 460 & & 253 \\
\hline Liqueur & 0,8 & 10,6 & & 4 & & 0,5 \\
\hline Bière, cidre & $\begin{array}{l}3,1 \text { bière } \\
0,9 \text { cidre }\end{array}$ & 9,3 bière & & 46 bière & & 46 bière \\
\hline Vinaigre & 2,1 & 31,9 & & ????? & & ????? \\
\hline Tuffeau & & $\begin{array}{c}11625 \\
\text { (465 bateaux) }\end{array}$ & & 10100 & & 10400 \\
\hline Ardoise & \multicolumn{2}{|c|}{$\begin{array}{c}<=\mathbf{2 2 5 1}=> \\
(5773000 \text { en nombre })\end{array}$} & \multicolumn{2}{|c|}{$<=2054,1=>$} & \multicolumn{2}{|c|}{$<=2580,6=>$} \\
\hline $\begin{array}{l}\text { Poisson de } \\
\text { rivière }\end{array}$ & & 38,8 tonnes & & 20,2 tonnes & & 37 tonnes \\
\hline $\begin{array}{l}\text { Poisson } \\
\text { de mer } \\
\text { (morues, } \\
\text { sardines) }\end{array}$ & $\begin{array}{c}1084,1 \mathrm{t} . \\
\text { (dont } 959 \mathrm{de} \\
\text { morues) }\end{array}$ & & $\begin{array}{l}\text { Chiffres peu } \\
\text { fiables } \\
\text { (hypothèse } \\
1100 \text { t.) }\end{array}$ & & $\begin{array}{l}\text { Chiffres peu } \\
\text { fiables } \\
\text { (hypothèse } \\
1100 \text { t.) }\end{array}$ & \\
\hline Bois & $\begin{array}{c}\mathbf{6 7 5} \text { bois de } \\
\text { chauffe et } \\
\text { construct. } \\
\mathbf{7 6 8 , 8} \text { fagots } \\
2,5 \text { lattes } \\
\text { 10,3 merrain } \\
32,5 \text { planches } \\
20 \text { tan }\end{array}$ & $\begin{array}{c}\mathbf{2 4 0 5 8} \text { bois } \\
\text { de chauffe } \\
\text { et construct. } \\
(9078,5 \text { charre- } \\
\text { tées }) \\
370 \text { lattes } \\
\mathbf{2 8 7 2} \text { merrain } \\
\mathbf{2 2 0 4} \text { tan } \\
557 \text { osier }\end{array}$ & $\begin{array}{l}7,5 \text { planches } \\
198,9 \text { t. mer- } \\
\text { rain } \\
424 \text { tonnes } \\
\text { fagots }\end{array}$ & $\begin{array}{c}\text { 4613, } 6 \text { bois } \\
55,4 \text { lattes } \\
\text { 3491, } 6 \text { mer- } \\
\text { rain } \\
1343,5 \text { tan } \\
108,7 \text { osier }\end{array}$ & $\begin{array}{c}\text { Bois : rien } \\
12,5 \text { planches } \\
\text { 123,5 merrain } \\
\text { 712 fagots } \\
2,5 \text { osier }\end{array}$ & $\begin{array}{c}\mathbf{7 4 5 9 , 7} \text { bois } \\
284,2 \text { lattes } \\
\mathbf{1 1 5 6 , 2} \text { mer- } \\
\text { rain } \\
124,5 \text { tan } \\
280,8 \text { osier }\end{array}$ \\
\hline
\end{tabular}


Emmanuel BrouARD

\begin{tabular}{|c|c|c|c|c|c|c|}
\hline Bouteilles & 2,06 & $\begin{array}{c}53,6 \text { (5583 dou- } \\
\text { zaines) }\end{array}$ & & & & \\
\hline $\begin{array}{l}\text { Faïence, porce- } \\
\text { laine }\end{array}$ & $\begin{array}{l}0,2 \text { faïence } \\
0,3 \text { porcel. }\end{array}$ & 32 faïence & 0,5 porcelaine & & 0,6 porcelaine & \\
\hline $\begin{array}{l}\text { Chanvre et } \\
\text { cordes }\end{array}$ & 123,3 chanvre & $\begin{array}{c}5,1 \mathrm{t} .+11 \\
\text { fournitures }\end{array}$ & & & & \\
\hline Foin & 13,6 & 31,5 & & 110,2 & & 85 \\
\hline $\begin{array}{l}\text { Textiles: draps } \\
\text { toiles serge } \\
\text { mercerie... }\end{array}$ & 17,5 & 1320 & 46,2 & 828,5 & 16,6 & 1034,7 \\
\hline $\begin{array}{l}\text { Divers (faux, } \\
\text { cire...) }\end{array}$ & $\begin{array}{c}2,2 \text { divers } \\
1,3 \text { galles } \\
26 \text { barriques }\end{array}$ & 188,8 & $\begin{array}{l}17,2 \text { divers, } \\
8,2 \text { galle, azur } \\
\text { et garance }\end{array}$ & 32,2 & 9 & 143,1 \\
\hline Cuirs divers & 15 & 72,9 & 59 & 65,45 & 169,5 & 90,1 \\
\hline Peltries & 0,2 & 8,7 & & & & \\
\hline Pierres à fusils & & 88 & & 35,1 & & 100 \\
\hline Tabac & & 178,1 & & 156,3 & & 169,8 \\
\hline $\begin{array}{l}\text { Pierres de } \\
\text { moulage }\end{array}$ & & $\begin{array}{c}\text { ?? (pour } \\
8838,50 \text { \&) }\end{array}$ & & & & \\
\hline Papier & 0,8 & 46,7 & 0,9 & 59 & 1,2 & 39,1 \\
\hline Sabots & & $\begin{array}{c}258 \\
\text { (1049 grosses) }\end{array}$ & & 283,6 & & 399 \\
\hline $\begin{array}{l}\text { Pots de terre } \\
\text { (pour raffi- } \\
\text { nage?) }\end{array}$ & 6,3 & 340 & & 198,9 & & 405,4 \\
\hline Fer, acier & 3,2 & 1701,2 & 0,8 & 1004,7 & $0,8 \mathrm{t}$. & 2235,3 \\
\hline Plomb, étain & 6,3 & 12,45 & 67,9 & 2,7 & 9,9 & 41,7 \\
\hline $\begin{array}{l}\text { Fer ouvragé, } \\
\text { chaudrons, } \\
\text { poêles, mar- } \\
\text { mites... }\end{array}$ & & 120 & & 32,2 & & 88,5 tonnes \\
\hline Quincaille & 0,8 & 253,7 & 1,8 & $106,9 \mathrm{t}$. & $0,1 \mathrm{t}$. & 20,4 \\
\hline Terre, sable & & 20 & & & & \\
\hline Ocre & & 133,4 & & 535,1 & & 1157,4 \\
\hline Brai, gras & 45,3 & & 51,1 & 1 & 48,1 & 0,8 \\
\hline Couperose & 2,5 & & 2,4 & & 0,5 & \\
\hline Souffre & 1 & & & & & \\
\hline $\begin{array}{l}\text { Charbon de } \\
\text { terre }\end{array}$ & 141 & $\begin{array}{c}\mathbf{4 7 3 , 5} \\
\text { (55,3 fourni- } \\
\text { tures) }\end{array}$ & 1525,5 & 77,1 & 1011,3 & 205,7 \\
\hline $\begin{array}{l}\text { Chaux } \\
\text { (descente) }\end{array}$ & $\begin{array}{c}1721,9(4679 \\
\text { pipes })<=\end{array}$ & & $\begin{array}{c}1671,5 \\
<=\end{array}$ & & $\begin{array}{c}3181 \\
<=\end{array}$ & \\
\hline Sirop mélasse & 14,8 & $\begin{array}{c}\mathbf{4 7 8 , 7} \\
\text { (pour } \\
57439 \text { livres) }\end{array}$ & & $\begin{array}{c}\mathbf{1 0 0 0} \\
\text { (120000 livres } \\
\text { à } 12 \text { livres le } \\
\text { cent) }\end{array}$ & & $\begin{array}{c}\mathbf{1 4 4 4 , 4} \\
\text { (130000 livres } \\
\text { à } 9 \text { livres le } \\
\text { cent) }\end{array}$ \\
\hline Sucre & $\begin{array}{c}\mathbf{2 1 0 6 , 3 6} \\
(+2043 \text { en } \\
\text { catégorie } \\
\text { épiceries })\end{array}$ & 4,5 & 246,8 & & 4163,5 & \\
\hline Droguerie & 503 & & 1017,9 & & 2797 & 21,8 \\
\hline
\end{tabular}


Quel commerce fluvial en Loire angevine au XVIII ${ }^{\mathrm{e}}$ siècle?

\begin{tabular}{|c|c|c|c|c|c|c|}
\hline $\begin{array}{l}\text { épiceries } \\
\text { diverses et } \\
\text { produits exo- } \\
\text { tiques }\end{array}$ & $\begin{array}{l}\mathbf{2 7 4 9 , 6} \text { (sucre, } \\
\text { indigo, café, } \\
\text { thé, alun, } \\
\text { teinture, } \\
\text { drogueries) + } \\
13,2 \text { indigo }+20 \\
\text { teintures }+34,1 \\
\text { savon } \\
+18,2 \text { alun }\end{array}$ & & $\begin{array}{c}41,2 \text { savon, } \\
31,1 \text { indigo } \\
16,7 \text { teinture, } \\
113,6 \text { café } \\
8,6 \text { bois d'inde } \\
10,3 \text { alun }\end{array}$ & & $\begin{array}{c}39,85 \text { savon } \\
0,2 \text { indigo } \\
\text { 14,9 teinture } \\
730,5 \text { café } \\
248,3 \text { bois } \\
\text { d'inde } \\
\text { 0,1 gomme } \\
\text { 1,32 alun }\end{array}$ & \\
\hline Résine & 1181,7 & & 1169,3 & 2,1 & $1240,1 t$ & 6,1 \\
\hline $\begin{array}{l}\text { TOTAUX } \\
\text { Valeurs mesu- } \\
\text { rées }\end{array}$ & 16220,4 & 62159,8 & 7446,9 & 51236,2 & 15979,8 & 69793 \\
\hline Sel & $10000 ?$ & & $11000 ?$ & & $11500 ?$ & \\
\hline $\begin{array}{l}\text { Marchandises } \\
\text { non évaluées }\end{array}$ & $\begin{array}{c}\mathbf{5 0 0 ? ?} \\
\text { (notam. } \\
206 \text { fournitures } \\
\text { de cercles, } \\
\text { pour } 1608 \text { \& } \\
\text { d'huîtres) }\end{array}$ & $500 ? ?$ & $\begin{array}{c}500 ? ? \\
\text { (notamment } \\
328 \text { fourn. de } \\
\text { cercles). }\end{array}$ & $\begin{array}{c}\mathbf{5 0 0 ? ?} \\
\text { (notam. } 196 \\
\text { fournitures de } \\
\text { cercles) }\end{array}$ & 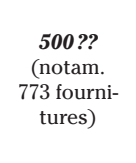 & $\begin{array}{c}500 ? ? \\
\text { (notam. } \\
14 \text { fournitures } \\
\text { de cercles) }\end{array}$ \\
\hline $\begin{array}{l}\text { Estimation } \\
\text { totale } \\
\text { (ordre de gran- } \\
\text { deur) }\end{array}$ & $\begin{array}{l}26720 \text { tonnes } \\
\left(9 / 10^{\mathrm{e}} \text { remon- }\right. \\
\text { tée) }\end{array}$ & $\begin{array}{c}\mathbf{6 2 6 5 9 , 8} \\
\text { tonnes } \\
\left(9 / 10^{\mathrm{e}} \text { des- }\right. \\
\text { cente) }\end{array}$ & $\begin{array}{c}20046,9 \\
\text { tonnes }\end{array}$ & $\begin{array}{c}51736,2 \\
\text { tonnes }\end{array}$ & $\begin{array}{c}29079,8 \\
\text { tonnes }\end{array}$ & $\begin{array}{l}70293 \\
\text { tonnes }\end{array}$ \\
\hline
\end{tabular}

Les chiffres correspondent à des tonnes, avec parfois, en complément et à titre d'exemple, la correspondance avec les unités d'origine.

Aux Ponts-de-Cé, les marchandises sont dirigées vers l'aval essentiellement (Nantes et Angers), sauf les ardoises qui circulent dans les deux sens. A Ingrandes, elles remontent vers l'amont, à l'exception de la chaux, dirigée vers la Bretagne.

Sources : Arch. mun. d'Angers, CC 202 (1753), CC 30 (1761), 31 et 32 (1766); Monique MerLET, Le péage..., op. cit., pour le dépouillement des journaux de 1761 et 1766. 


\section{Annexe 6 - Marchandises déclarées aux bureaux de la Haute chaine et de La Pointe (1753, 1761 et 1766)}

\begin{tabular}{|c|c|c|c|c|c|c|}
\hline & \multicolumn{2}{|l|}{1753} & \multicolumn{2}{|l|}{1761} & \multicolumn{2}{|l|}{1766} \\
\hline & $\begin{array}{l}\text { Haute chaine } \\
<=\text { (manque } \\
\text { février) }\end{array}$ & $\begin{array}{l}\text { La Pointe } \\
\text { Remontée } \\
=>\text { (janv. à } \\
\text { septembre) }\end{array}$ & $\begin{array}{l}\text { Haute chaine } \\
\text { Descente } \\
<=\end{array}$ & $\begin{array}{l}\text { La Pointe } \\
\text { Remontée => }\end{array}$ & $\begin{array}{l}\text { Haute chaine } \\
\text { Descente } \\
<=\end{array}$ & $\begin{array}{l}\text { La Pointe } \\
\text { Remontée } \\
=>\end{array}$ \\
\hline Céréales & 82,1 & 115,8 & 104 (5/4e blé) & 46,1 & $\begin{array}{l}220,7 \\
(4 / 5 \mathrm{e} \text { blé})\end{array}$ & \\
\hline Farine & 310,90 & 65,2 & 427,3 & & $466,9 \mathrm{t}$. & 1 tonne \\
\hline $\begin{array}{l}\text { Autres } \\
\text { aliments }\end{array}$ & $\begin{array}{l}\text { Noix } 18 \\
\text { Aloses } 3,9 \\
\text { Pommes, } \\
\text { châtaig. 84,6 }\end{array}$ & & $\begin{array}{l}\text { Noix } 55,8 \\
\text { Pommes, châ- } \\
\text { taignes } 42,7\end{array}$ & & $\begin{array}{l}\text { Noix } 32,1 \mathrm{t} \text {. } \\
\text { Pommes, châ- } \\
\text { taignes } 9,9\end{array}$ & \\
\hline $\begin{array}{l}\text { Liquides } \\
\text { (poids net) }\end{array}$ & $\begin{array}{l}\text { Vin } 33,9, \\
\text { vinaigre } 54,1 \\
\text { Cidre } 81,9\end{array}$ & Vin : 811,2 & Vin $53,6 \mathrm{t}$. & 2697,9 & Vin 11,7 & 763,8 \\
\hline Bois divers & $\begin{array}{l}\text { A bruler } \\
\text { 9803,5 } \\
\text { D'ouvrage, ma- } \\
\text { rine, planches } \\
\mathbf{7 6 8 0} \\
\text { Merrain } \\
\mathbf{2 2 9 1 , 4} \\
\text { Lattes } 139,6 \\
\text { Tan } 26,5 \\
\mathbf{1 9 9 4 0 , 8} \boldsymbol{t} .\end{array}$ & 2453,9 tonnes & $\begin{array}{l}\text { Bois sans } \\
\text { précision : } \\
\text { 9126,1 } \\
\text { Mairain } \\
\mathbf{3 6 7 4 , 4} \\
\text { Lattes } 12,7 \\
\text { Tan } 127,2 \mathrm{t} \\
\\
\\
\mathbf{1 2 9 4 0 , 4 t}\end{array}$ & $\begin{array}{l}\text { Pas de bois } \\
\text { signalé }\end{array}$ & $\begin{array}{l}\text { Bois sans } \\
\text { précision : } \\
\text { 12521,2 } \\
\text { Mairain } \\
1 \text { 639,6 } \\
\text { Lattes } 7,8 \\
\text { Tan } 376,3 \\
\\
\\
\\
\mathbf{1 4 5 4 4 , 9} \text { t. }\end{array}$ & $\begin{array}{l}\text { Pas de bois } \\
\text { signalé }\end{array}$ \\
\hline $\begin{array}{l}\text { Carreaux } \\
\text { et pierres } \\
\text { des Rairies } \\
\text { (Nantes) }\end{array}$ & $\begin{array}{l}\text { Carreaux } \\
\text { 2 701,7 } \\
\text { Briques } 174,3 \\
\text { Pierres } 180,2\end{array}$ & & \begin{tabular}{|l} 
Carreaux \\
$\mathbf{5 8 8 , 5}$ \\
Pierres 95,4 \\
Briques :?
\end{tabular} & & $\begin{array}{l}\text { Carreaux } \\
\mathbf{2 2 2 6 , 2} \\
\text { Pierres } 95,8\end{array}$ & \\
\hline Divers & $\begin{array}{l}\text { Sailleries } 163 \\
\text { Tonneaux } 38,1 \\
\text { Poteries } 27,9 \\
\text { Foin } 231,1 \\
\text { Fer } \mathbf{4 3 4 , 7} \\
\text { Charbon } 12,45 \\
\text { Chaux } 26 \text { etc. }\end{array}$ & $\begin{array}{l}\text { Charbon } 240 \\
\text { Chaux } 299,5 \\
\text { Papier } 4,5 \\
\text { Foin : } 29,4 \\
\text { Graines de lin } \\
32,1\end{array}$ & $\begin{array}{l}\text { Tonneaux } 99,8 \\
\text { Foin } 270,9 \\
\text { Toiles } 10,8 \\
\text { Cuirs et peaux } \\
7,7 \\
\text { Fer } \mathbf{4 7 0} \\
\text { etc. }\end{array}$ & $\begin{array}{l}\text { Charbon } 77,1 \\
\text { Chaux } 285,9 \\
\text { Papier } 3 \\
\text { Graines lin } 2,3 \\
\text { Foin } 36,7 \\
\text { etc. }\end{array}$ & $\begin{array}{l}\text { Tonneaux } 54 \\
\text { Foin } 252 . \\
\text { Toiles } 9,9 \\
\text { Cuirs et peaux } \\
5,4 \\
\text { Fer } \mathbf{3 1 0 , 9} \\
\text { etc. }\end{array}$ & $\begin{array}{l}\text { Charbon } 34,3 \\
\text { Chaux } 409,6 \\
\text { Papier } 3,4 \\
\text { Graines de } \\
\text { lin } 3,4 \\
\text { etc. }\end{array}$ \\
\hline $\begin{array}{l}\text { TOTAUX } \\
\text { (mesure) }\end{array}$ & $\begin{array}{l}24687 \\
\text { (bois } 81 \% \text { ) }\end{array}$ & 4069,1 & $\begin{array}{l}\text { 15265,4 } \\
\text { (bois } 84,8 \% \text { ) }\end{array}$ & $\begin{array}{l}\mathbf{3 1 5 0 , 4} \\
(\operatorname{vin} 85,6 \%)\end{array}$ & $\begin{array}{l}18417,3 \\
\text { (bois } 79 \% \text { ) }\end{array}$ & $\begin{array}{l}\text { 1216,4 } \\
\text { (vin } 62,8 \% \text { ) }\end{array}$ \\
\hline $\begin{array}{l}\text { March. non } \\
\text { évaluées }\end{array}$ & $\begin{array}{l}300 ? ? \text { (nota. } \\
1641,25 \text { four. de } \\
\text { cercles) }\end{array}$ & $50 \mathrm{t} . ?$ & $\begin{array}{l}300 ?(1921 \\
\text { fournitures de } \\
\text { cercles) }\end{array}$ & & $\begin{array}{l}300 ? \\
\text { (1169 fourn. de } \\
\text { cercles) }\end{array}$ & \\
\hline SOUS-TOTAL & 24987 tonnes & 4119,1 tonnes & $\begin{array}{l}\text { 15565,4 } \\
\text { tonnes }\end{array}$ & 3150,4 tonnes & $\begin{array}{l}18717,3 \\
\text { tonnes }\end{array}$ & 1216,4 tonnes \\
\hline
\end{tabular}

Les chiffres correspondent à des tonnes. À la Haute Chaîne (Angers), les marchandises sont dirigées vers l'aval et principalement vers Nantes. À La Pointe (confluence avec la Loire), elles sont dirigées vers Angers et vers le Maine.

Sources : Arch. mun. d'Angers, CC 202 (1753), CC 30 (1761), 31 et 32 (1766); Monique MerLET, op. cit., pour le dépouillement des journaux de 1761 et 1766 . 


\section{Précisions relatives aux annexes 5 et 6}

Voici quelques exemples de conversions nécessaires pour arriver à des évaluations de la masse des marchandises.

ARDolses : cent ardoises d'Angers pèsent en moyenne 38,18 kg (BraRD, C. P., Minéralogie appliquée aux arts..., tome 2, Paris, Levrault, 1821, p. 180).

BLÉ ET FÈVES : les céréales sont comptées en muid, septier ou livres. Le septier vaut 12 boisseaux à la mesure des Ponts-de-Cé (mesure de référence en Anjou). Le boisseau des Ponts-de-Cé fait 16,972 litres, et pèse 25 livres pour le blé, 23 pour le seigle, 22 l'orge (Peuchet, Jacques, Dictionnaire universel..., op. cit., tome 2, p. 750). Le muid n'est pas utilisé habituellement en Anjou pour les céréales. On utilise très probablement ici celui de Paris, pesant autour de 2900 livres (Arch. dép. de Loire-Atlantique, C 227). Le tonneau de blé pèse à Nantes 2200 livres, celui d'orge et seigle 2000 livres, et celui de grosses fèves 2560 livres (Peuchet, Jacques, Ibid., tome 5, p. 205-211). Ces différences de poids à volume égal, confirmées par d'autres sources, permettent d'évaluer la masse d'un muid de fèves.

BoIs : en Mayenne et en Sarthe, une charretée de bois de chauffage fait respectivement 3,120 stères et 3,5 stères. Poids du chêne et hêtre de $800 \mathrm{~kg} / \mathrm{m} 3$ environ (voir note 85 ). Certains auteurs indiquent $700 \mathrm{~kg}$, mais le bois des radeaux est loin d'être sec.

CHARBON : la pipe fait $408,1 \mathrm{~kg} 1$ pied cube pèse 60 à 65 livres, 1 pipe fait 460 litres. (BERTRAND, J.E., Descriptions des arts et métiers..., tome 16, Neuchatel, 1780, p. 476).

CHARGE : une charge (ou charge de cheval) pèse par convention 300 livres pesant.

FARINE : aux Ponts-de-Cé, en barils de 90 à 100 kg d'après de nombreux ouvrages. À la Haute Chaîne, la farine est évaluée en septiers. Un septier de farine a une masse volumique égale à $75 \%$ de celle d'un septier de froment.

VIN : les busses (en Anjou) et poinçons (en amont) contiennent plus ou moins 230 litres, et la pipe 460 litres. Le poids d'une busse vide est d'environ $33 \mathrm{~kg}$, contre $40 \mathrm{ou} 45 \mathrm{~kg}$ pour une barrique bordelaise de contenance à peu près équivalente, mais plus robuste.

OSIER : bottes de $25 \mathrm{~kg}$ (BIXIo, Alexandre, Journal d'agriculture pratique..., tome 1, Paris, 1837 p. 154). MERRAIN : millier de $2540 \mathrm{~kg}$. (THOMAs, Jean-Bazile, Traité général de statistique, culture et exploit des bois, 1840, p. 67). D'autres ouvrages indiquent 3000 à $3500 \mathrm{~kg}$ pour faire avec le même nombre de pièces à peu près, des barriques de Bordeaux, plus lourdes que celles de la vallée de la Loire (voir VIN).

MORUES : cent de morue verte composé de 124 morues ou 62 poignées de 2, pesant 600 à 900 livres aux deux premières qualités (SAVARY, Dictionnaire universel de commerce, 1723, tome 2, article Morue, p. 795).

PEAUX : les cuirs de bœuf pèsent 23 livres, les cuirs de vache et de cheval, 9 livres, la douzaine de veaux, 18 livres (BerTRAND, J.E., Description des arts et métiers... tome 3, p. 127).

SABOTS : grosse de 156 paires, évaluée $246 \mathrm{~kg}$. 


\section{RÉSUMÉ}

Au XvIII ${ }^{\mathrm{e}}$ siècle, les villes de la Loire entretiennent grâce au transport fluvial des échanges commerciaux intenses. Dans la partie aval, Nantes en particulier joue un rôle central dans ce commerce. Son hinterland s'étend très loin en amont, jusqu'à Orléans. Son grand port maritime approvisionne le bassin de la Loire en sel, en produits des colonies ou du midi, en poissons, et parfois en blé. Orléans est un relais vers Paris, l'Est et le Lyonnais. En sens inverse, Nantes reçoit beaucoup de blés et de tuffeaux de l'Anjou, du bois, du vin et de nombreuses autres marchandises de tout le bassin ligérien. Les trois quarts du trafic se font à la descente. L'utilisation de sources variées, et en particulier des journaux du péage dit de la " cloison d'Angers ", permet de donner un ordre de grandeur du trafic descendant et remontant au milieu du $\mathrm{XVIII}^{\mathrm{e}}$ siècle. La comparaison avec les évaluations du trafic maritime fait ressortir l'importance du trafic fluvial du port de Nantes.

\section{ABSTRACT}

Transport by inland waterway helped develop the commercial activity of the Loire Valley during the 18th century. Nantes in particular, located downstream, played a major part in this business. Its hinterland spread upstream as far as Orleans. The great seaport supplied the Loire basin with salt, goods from the Colonies and Southern France, as well as fish and sometimes wheat. Orléans had links with Paris, the East and the Lyon area. In the opposite direction, Nantes received considerable quantities of wheat and tuffeau stone from Anjou, as well as wood, wine, and many other goods from the river basin. Three-quarters of the traffic went downstream. Various sources, and notably the toll register of the "cloison d'Angers", allow a rough estimate of river traffic downstream and upstream in the middle of the $18^{\text {th }}$ century. The comparison with sea traffic estimations at the same time underlines the importance of river transport in Nantes. 